\title{
Coriolis Mass Flow Metering for Three-Phase Flow: A Case Study
}

Manus Henry, Michael Tombs, Mayela Zamora, Feibiao Zhou, University of Oxford

Corresponding Author: $\quad$ Manus Henry

Department of Engineering Science

Parks Road, Oxford OX1 3PJ.

Tel +44 1865273913

Fax +44 1865273021

manus.henry@eng.ox.ac.uk

\begin{abstract}
Previous work has described the use of Coriolis mass flow metering for two-phase (gas/liquid) flow. As the Coriolis meter provides both mass flow and density measurements, it is possible to resolve the mass flows of the gas and liquid in a two-phase mixture if their respective densities are known. To apply Coriolis metering to a three-phase (oil/water/gas) mixture, an additional measurement is required. In the work described in this paper, a water cut meter is used to indicate what proportion of the liquid flow is water. This provides sufficient information to calculate the mass flows of the water, oil and gas components. This paper is believed to be the first to detail an implementation of three-phase flow metering using Coriolis technology where phase separation is not applied.
\end{abstract}

Trials have taken place at the UK National Flow Standards Laboratory three-phase facility, on a commercial three-phase meter based on the Coriolis meter / water cut measurement principle. For the 50mm metering system, the total liquid flow rate ranged from $2.4 \mathrm{~kg} / \mathrm{s}$ up to $11 \mathrm{~kg} / \mathrm{s}$, the water cut ranged from $0 \%$ to $100 \%$, and the gas volume fraction (GVF) from 0 to 50\%. In a formally observed trial, 75 test points were taken at a temperature of approximately $40{ }^{\circ} \mathrm{C}$ and with a skid inlet pressure of approximately $350 \mathrm{kPa}$. Over $95 \%$ of the test results fell within the desired specification, defined as follows: the total (oil + water) liquid mass flow error should fall within $\pm 2.5 \%$, and the gas mass flow error within $\pm 5.0 \%$. The oil mass flow error 
limit is $\pm 6.0 \%$ for water cuts less than $70 \%$, while for water cuts between $70 \%$ and $95 \%$ the oil mass flow error limit is $\pm 15.0 \%$.

These results demonstrate the potential for using Coriolis mass flow metering combined with water cut metering for three-phase (oil/water/gas) measurement.

Keywords: Coriolis; Mass Flow; Neural Net; Multi Phase Flow; Two Phase Flow; Oil and Gas. 


\section{Highlights}

- A three-phase metering skid is described, based on Coriolis Mass Flow and Water Cut metering.

- Formal trials have taken place at the UK National Flow Laboratory, TUV-NEL.

- The water cut ranged from 0 to $100 \%$ and the gas volume fraction ranged from 0 to $50 \%$.

- The liquid mass flow error was within $\pm 2.5 \%$, and the gas mass flow error within $\pm 5.0 \%$.

- The oil mass flow error was $\pm 6.0 \%$ for water cuts less than $70 \%$. 


\section{Introduction}

Coriolis mass flow metering is a widely-used technique for industrial flow measurement. A Coriolis meter consists of an electronic transmitter and a mechanical flow tube. The meter operates by oscillating the flow tube (typically 1-300 mm in diameter), at the natural frequency of a selected mode of mechanical vibration. Two sensors monitor the flow tube vibration as the process fluid passes through. The frequency of oscillation (in the range $50 \mathrm{~Hz}-1 \mathrm{kHz}$ depending on flow tube geometry) is determined by the overall mass of the vibrating system. For a given flow tube of fixed mass, the overall mass (flow tube plus process fluid) varies with the density of the process fluid. Accurate determination of the frequency of vibration thus enables the process fluid density to be calculated. The geometry of the flow tube is further arranged so that Coriolis forces act to generate a phase difference between the two sinusoidal sensor signals, which is essentially proportional to the mass flow of the process fluid. The Coriolis transmitter, which monitors and maintains flow tube oscillation, extracts the sensor signals and derives the flow and density measurements.

The last decade has seen rapid developments in Coriolis mass flow metering with the introduction of digital technology to implement key aspects of transmitter functionality, particularly the generation of the drive signal [1, 2, 3]. Enhancements have included improving the dynamic response of the meter [4, 5, 6]. However, perhaps the most important recent development has been establishing the capability of Coriolis meters to measure two-phase flows. Previous Coriolis metering transmitters were unable to maintain flow tube oscillation in the highly damped conditions generated by the mixing of liquid and gas. However, using a digital drive, it has proved possible to continue operation through most gas/liquid mixtures, including the onset of liquid into an empty flow tube and the draining of a full flow tube back to the empty state. Unfortunately, maintaining oscillation is insufficient to ensure good measurement, as two-phase (gas/liquid) conditions induce potentially large errors into the mass flow and density measurements. However, it has proved possible to model these errors, based on parameters observable within the meter itself, and a number of two-phase flow Coriolis applications have been developed [7]. 
Several physical approaches to modelling the effects of two-phase flow have been reported in the literature, of which the most important are: the inertial/buoyancy effect $[8,9]$, the compressibility effect $[10,11]$ and the (asymmetric) damping effect $[12,13]$. While the development of such physical models is essential, they are unable at present to give good predictions of mass flow and density errors over practical industrial conditions. Nevertheless, the repeatability of such errors indicates that valuable measurements can be provided, and accordingly in this study a purely empirical approach is adopted. The error behaviour is recorded, modelled, and predicted, based on internally observed parameters, without assuming any particular physical process underlies the effect.

As discussed in more detail below, further steps are required to attempt three-phase measurement, where the liquid component is further separated into measurements of (usually) oil and water. This is believed to be the first description of such a system developed by an academic group; however, given the substantial commercial interest in three-phase flow within the oil and gas industry, there have been a number of commercial developments, typically involving partial separation. For example, Agar Corporation has developed a commercial system using a similar combination of Coriolis and water cut meters [14].

A first approach to the empirical modelling of two-phase flow effects in a Coriolis meter [15] is to consider the mass of the gas to be negligible; this is a reasonable assumption for low pressure applications where only the mass flow of the liquid is of interest. Assuming a constant true liquid density, the two-phase flow can be characterised by the true liquid mass flow rate and the Gas Volume Fraction (GVF), defined as the percentage of gas by volume. A variety of parameters internal to the Coriolis meter may be used to correct the mass flow and density readings and to provide a corrected liquid mass flow and an estimate of the GVF. These include the observed mass flow rate and density, the "density drop" i.e. the drop in density from a configured liquid-only density (as discussed below) and the drive gain.

A second approach to modelling two-phase flow is to consider both the liquid and gas mass flows [16]. This can prove necessary in high GVF and/or high pressure applications, where the mass of gas is not negligible, 
or where the flow rate of gas itself is of interest. Here additional information is needed. To perform PVT calculations for the gas, knowledge of the gas density is required (for example based on its composition), along with on-line readings of temperature and pressure. Composition and/or density information for gas and liquid (and how these vary with temperature and pressure) can be considered part of the system configuration, while on-line readings of temperature and pressure require additional instrumentation. Models of mass flow and density errors can be reworked to take the mass of gas into account, and the resulting calculation of liquid mass flow and GVF can be transformed to provide the mass flow of both the liquid and gas phases.

An obvious extension is to provide three-phase metering for the upstream oil and gas industry, where the three phases are water, oil and gas respectively. To a first approximation, this can be treated as a two phase (liquid/gas) problem, where the density of the liquid varies with the water cut. Here water cut is taken to represent the proportion by volume of the water in the total liquid. Thus if the water cut is $0 \%$, the liquid is pure oil (irrespective of GVF) and if the water cut is 100\%, the liquid is pure water (irrespective of GVF). In practice it is now possible to measure the water cut of a three-phase mixture with reasonable accuracy (for example the device used in this paper is specified as having $\pm 3 \%$ absolute error in water cut reading, for water cut less than 95\% [17]) using a commercial water cut meter, and it is further possible to include water cut variation in the modelling of the mass flow and density errors; accordingly a three-phase metering system based on Coriolis mass flow metering has been developed. As previously, measurement of temperature and pressure are required for PVT calculations, while the configuration data must be extended to provide the densities of the pure water and pure oil, together with their variations with temperature and pressure.

A three-phase mixture can be specified in a number of ways; two will be used frequently throughout this paper. The first is to specify the mass flows of the oil, water and gas components; at the low operating pressures used in this work the oil and water flows are stated in $\mathrm{kg} / \mathrm{s}$, while the gas flow rate is stated in $\mathrm{g} / \mathrm{s}$. The alternative description is to specify the total liquid flow rate (usually in $\mathrm{kg} / \mathrm{s}$ ), water cut (between $0 \%$ 
and $100 \%$ ) and GVF (from $0 \%$ up to $50 \%$ and beyond). Where it is assumed that the density of each phase is known along with temperature and pressure conditions, and that there is no slip between phases, it is straightforward to convert from one of these specifications to the other. Typically, the first description (mass flows of each phase) is used for specifying the accuracy of final results, while the latter description (liquid flow/water cut/GVF) is used for describing experimental conditions, particularly during model development.

In this paper we describe a three-phase metering system which combines Coriolis mass flow metering with a water cut measurement to provide separate measurements of oil, water and gas flow. While the long-term goal of our research is to develop a Coriolis-based solution to cover the complete range of three-phase conditions, our experience suggest the best performance is obtained by designing particular implementations for more limited operating envelopes. The current system is designed for good measurement performance at up to $50 \%$ GVF, for any water cut, and with a 6:1 turndown on the liquid mass flow rate.

An overview of the three-phase metering system is provided in section 2. Aspects of the three-phase modelling of mass flow and density errors are described in section 3. Trials at TUV-NEL's multi-phase flow facility in the UK are explained in section 4, while the results are summarised in section 5.

\section{$2 \quad$ Net Oil and Gas Skid Overview}

The term 'Net Oil' is used in the upstream oil and gas industry to describe the oil flow rate within a threephase or a liquid (oil/water) stream. A Net Oil and Gas Skid (from here on referred to as the Skid) would be expected to measure the oil and gas flow-rates, and hence also the produced water, in a three-phase produced fluid. The Skid has been designed by the authors and their industrial associates as a replacement for three-phase separator measurement systems conventionally used for well testing and production monitoring in the field. The Skid has been used in pilot trials in oil field applications; this work will be described in future publications. 
Figure 1 shows the design of the Skid. The pipework dimensions and internal diameter $(50 \mathrm{~mm})$ are the same for a range of Coriolis meter inlet diameters from $15 \mathrm{~mm}$ to 50mm. Adaptors are provided on the down-leg to accommodate flow tubes smaller than $50 \mathrm{~mm}$ diameter; all experimental work described in this paper is for the 50mm flow tube, but similar trials and results have been carried out for a $15 \mathrm{~mm}$ flow tube at NEL, and a new skid design with 80mm flow tube and pipework has been tested at the VNIIR Institute for Flow Metering, a Russian National Flow Laboratory.

The process fluid flow is conditioned to minimise slip through the rising and falling of the pipework and by an integrated flow straightener [17] in the horizontal top section, with the Coriolis meter positioned on the downward and outward leg of the skid. The water cut meter is placed immediately below it. The design was developed through field experience with low pressure well testing applications, and helps to ensure that where flow rates are low, liquid passes through the Coriolis meter in relatively substantial slugs, which provides better measurement performance; a discussion of Coriolis meter performance with two-phase slugging is presented in [7]. This paper describes two-phase trials at NEL working with nitrogen gas and a high viscosity (200cSt) oil, in which only liquid flow measurement is provided. At GVFs above 40\%, significant slugging was observed, but the Coriolis meter was able to track the slugs successfully and over $80 \%$ of test measurements fell within $2 \%$ liquid mass flow accuracy.

In addition to the Coriolis flow tube and transmitter, the instrumentation on the skid consists of the water cut meter and a pressure and temperature transmitter. The latter reads the pressure at the inlet to the Coriolis meter and the temperature of an RTD (resistance temperature detector) sensor in a thermal well, positioned at the top of the skid. The Communications / Compute Unit acts as a communication master for all the devices, using the Modbus RTU industrial communications protocol, commonly used in the oil and gas industry. The compute unit performs three-phase flow measurement calculations based on the data received, provides a user interface (for providing, for example, gas and fluids density information) and also carries out data archiving. Real-time data is available to the user's data acquisition system via a Modbus interface, with an update rate of 1 second. 
The pressure and temperature measurements are based on standard industrial sensing technology, with uncertainties of $0.05 \%$ for the absolute pressure and $0.28{ }^{\circ} \mathrm{C}$ for temperature. While these measurements are made available to the user via the Modbus interface they are essentially mundane and, other than their role in providing PVT calculations for the gas phase and density calculations for the liquid phases, are not considered further.

Several water cut meter technologies have been evaluated for measurement accuracy when gas is present in the process fluid. The chosen meter [18] provides a good measurement of water cut which may be further improved using error correction techniques similar to those described in section 3. The device operates using near-infrared absorption spectroscopy, with four or five wavebands measured simultaneously to distinguish water, oil, gas and other components. The water cut meter was calibrated using samples of the NEL flow loop water and oil, following the manufacturer’s instructions for the device.

The Hardware/Software architecture of the Skid is shown in Figure 2. The Display Computer provides three communication interfaces: an internal Modbus for the Skid instrumentation, an external Modbus interface to provide final measurement values to the user, and an Ethernet interface to enable remote configuration, monitoring and archival data retrieval. The Display Computer further provides a touch screen user interface to enable local configuration, data display, etc.

Figure 2 further shows an overview of the flow calculation algorithm. The uncorrected data from the instruments is gathered via the Modbus interface. Here, 'uncorrected' refers to the effects of multi-phase flow: the mass flow, density and water cut readings are calculated based on their single-phase calibration characteristics. The liquid and gas densities are calculated based on the temperature, pressure and water cut readings and configuration parameters, based on data provided by NEL. Corrections are applied to the Coriolis meter mass flow and density readings based on the three-phase flow measurement models. Finally, 
the oil, water and gas measurements are calculated from the corrected mass flow, density and water cut readings.

Given regular updates of the following measurements from the instruments:

$$
\begin{aligned}
& \rho_{m a} \quad \text { the apparent mixture density from the Coriolis mass flow meter }\left(\mathrm{kg} / \mathrm{m}^{3}\right) \\
& \dot{m}_{m a} \quad \text { the apparent mass flow rate from the Coriolis mass flow meter }(\mathrm{kg} / \mathrm{s}) \\
& w c \quad \text { the water cut from the water cut meter, after any correction has been applied (\%) } \\
& T \quad \text { the process fluid temperature from the RTD sensor (K) } \\
& P \quad \text { the absolute pressure at the inlet to the Coriolis mass flow meter, measured by the pressure } \\
& \quad \text { sensor }(\mathrm{kPa}),
\end{aligned}
$$

the following calculations are carried out. Firstly, the fluid densities are calculated based on configured parameters, and the latest temperature and pressure measurements. These calculations may be specified in full or in part by national standards (e.g. AGA-8/ISO 12213[19], or MP113[20] for gas, or API MPMS Chapter 11.1-2004 [21] for liquids).

$$
\begin{aligned}
& \rho_{g}=\text { function }_{\text {gas }}(\text { config }, T, P) \\
& \rho_{o}=\text { function }_{\text {oil }}(\text { config }, T, P) \\
& \rho_{w}=\text { function }_{\text {water }}(\text { config }, T, P),
\end{aligned}
$$

where $\rho_{g}, \rho_{o}$ and $\rho_{w}$ are the densities of the gas, oil and water respectively, and config is the configuration data providing density information for each fluid.

Next, the density of the liquid-only mixture $\rho_{l}$ is calculated, based on the water cut:

$\rho_{l}=\frac{w c}{100} \rho_{w}+\frac{100-w c}{100} \rho_{o}$ 
The apparent density of the three-phase mixture $\rho_{m a}$, is lower than $\rho_{l}$ if any gas is present. A useful parameter is the density drop $d d$, the percentage difference between the liquid-only mixture density $\rho_{l}$ and the observed density $\rho_{m a}$

$d d=\frac{\left(\rho_{l}-\rho_{m a}\right)}{\rho_{l}} \cdot 100 \%$

Intuitively, $d d$ is related to the GVF, increasing from zero as the gas proportion increases from zero in the three-phase mixture. However as the GVF can only be calculated accurately after corrections have been applied to the mass flow and density readings, the $d d$ provides a useful index of gas content for the purposes of generating corrected mass flow and density values.

The next step of the calculation is to generate the corrected three-phase mixture mass flow $\dot{m}_{m c}$ and density $\rho_{m c}$ measurements, based on the three phase neural net (NN) models as discussed in more detail in section 3.

$$
\begin{aligned}
& \dot{m}_{m c}=N N_{m}\left(\dot{m}_{m a}, \rho_{m a}, w c, d d, \ldots\right) \\
& \rho_{m c}=N N_{\rho}\left(\dot{m}_{m a}, \rho_{m a}, w c, d d, \ldots\right)
\end{aligned}
$$

In effect, equations (4) and (5) provide three-phase calibration curves, mapping apparent density and mass flow values to corrected density and mass flow values. The accuracy of the results depends upon the repeatability of these calibration curves under the range of three-phase conditions for which they are used.

Given $\dot{m}_{m c}, \rho_{m c}$ and $w c$ (and hence $\rho_{l}$ ), the mass flow rates of each of the individual components can now be calculated. The gas volume fraction based on corrected data, $\alpha_{c}$, is calculated as:

$$
\alpha_{c}=\frac{\rho_{l}-\rho_{m c}}{\rho_{l}-\rho_{g}} \cdot 100 \%
$$


The mass flows of the gas $\dot{m}_{g}$ and liquid $\dot{m}_{l}$ are calculated as follows:

$$
\begin{aligned}
& \dot{m}_{g}=\frac{\alpha_{c}}{100 \%} \frac{\rho_{g}}{\rho_{m c}} \cdot \dot{m}_{m c} \\
& \dot{m}_{l}=\frac{100-\alpha_{c}}{100 \%} \frac{\rho_{l}}{\rho_{m c}} \cdot \dot{m}_{m c}
\end{aligned}
$$

Finally, the mass flows of the oil $\dot{m}_{o}$ and water $\dot{m}_{w}$ are deduced from the total liquid using the water cut, as follows. It will be recalled that the water cut is a volumetric, rather than a mass-based, calculation.

$$
\begin{aligned}
& \dot{m}_{w}=\frac{w c}{100 \%} \frac{\rho_{w}}{\rho_{l}} \cdot \dot{m}_{l} \\
& \dot{m}_{o}=\frac{100-w c}{100 \%} \frac{\rho_{o}}{\rho_{l}} \cdot \dot{m}_{l}
\end{aligned}
$$

Thus the mass flows of gas, oil and water are calculated based on the Coriolis and water cut measurements.

\section{$3 \quad$ Three-Phase Flow Measurement Models}

Given the straightforward calculations of three-phase flow outlined in the previous section, the primary technical challenge is to correct for the potentially large errors induced in the mass flow and density measurements of a Coriolis meter by the effects of a gas/liquid mixture. As described in [7], factors such as the geometry and orientation of the Coriolis flow tube influence the error functions. For a fixed flow tube geometry and orientation, the most significant dynamic parameters are the liquid flowrate and the GVF. Previous work (e.g. [15]) has described how these errors can be modelled so that corrections can be applied based solely on parameters observable within the Coriolis meter itself. While a number of approaches are possible, here Neural Nets (NNs) are used for modelling purposes. Thus a series of experiments are carried out to create a range of mass flow, GVF and water cut conditions, where the resulting mass flow and density errors are modelled based on internally observed parameters.

The training data set was developed using 10\% WC steps, typically 8 flow rate steps from a maximum of $11 \mathrm{~kg} / \mathrm{s}$ down to $2 \mathrm{~kg} / \mathrm{s}$, and up to $8 \mathrm{GVF}$ points up to $50 \%$, limited by a maximum differential pressure across the flowtube of $150 \mathrm{kPa}$. Thus, at lower flow rates, data for GVF up to $50 \%$ was collected, but at high flow 
rates, the GVF was limited by the differential pressure across the flow tube. These same limits were reflected in the test matrix - see Figure 12. Given the large data set, which was intended to provide reasonable coverage of the entire operating range of the skid, data recording at each training point was limited to 120s, which was found to be sufficient for model-building purposes. The temperature range was similar for the collection of the training data set and for the formal trials, all falling within the range $32^{\circ} \mathrm{C}$ $43^{\circ} \mathrm{C}$. Similarly, the supply pressure for training and testing data all fell within the range $280 \mathrm{kPa}-460 \mathrm{kPa}$ (a few test points with 0\% GVF fell outside this pressure).

For example, figures 3 and 4 show the mass flow and density errors for the 50mm Coriolis meter (positioned within the Skid), with water cut varying from 0 to $100 \%$ in steps of $10 \%$, where the true mass flow rate is maintained at $6.3 \mathrm{~kg} / \mathrm{s}$, and where the GVF is increased up to 50\%. Similarly, figures 5 and 6 show the same errors with the mass flow rate kept at $4.0 \mathrm{~kg} / \mathrm{s}$. This data was collected at TUV-NEL as described in the next section. These graphs show the influence of GVF and water cut on the mass flow and density errors. While the broad pattern of behaviour is similar for all graphs, with GVF having the most significant influence on the mass flow and density errors, both water cut and the flow rate itself introduce further variation-.

Of course when the Skid is operating in real-time the true GVF is not available, however the density drop (i.e. the observed drop in density reading from the pure liquid density as a result of gas entrainment) is observable. The same data are shown in figures $7-10$ with density drop as the $\mathrm{x}$ axis. Such data is used to build NNs to predict the mass flow and density errors, given the observed raw mass flow rate and density drop. Further details of the techniques used to model the multiphase error surfaces are given in [16], such as handling the interaction between models of the Coriolis meter errors and the water cut meter error. This patent further includes discussion of the use of superficial velocity to model flow meter behaviour where slip is significant.

\section{FORMAL TRIALS AT TUV-NEL}


A formal series of trials were carried out on a 50mm Skid in January 2012 at TUV-NEL's three-phase flow facility. The intention was to demonstrate compliance with the measurement performance requirements of the Russian Standard GOST 8.165 [22], which has the following key specifications:

- $\quad$ Total liquid flow accuracy requirement $\pm 2.5 \%$

- Total gas flow accuracy requirement $\pm 5.0 \%$

Total oil flow accuracy requirement dependent upon water cut:

o $\quad$ For water cuts less than $70 \%$, oil accuracy requirement $\pm 6.0 \%$

o $\quad$ For water cuts between $70 \%$ and $95 \%$, oil accuracy requirement $\pm 15.0 \%$

o $\quad$ For water cuts above 95\%, no oil accuracy requirement is specified, but an indication of performance may be given.

It is understood that the requirement for gas accuracy is a relatively recent introduction to the standard, and it is noteworthy that the gas accuracy requirement is not specified on a sliding scale, while the oil accuracy does vary with water cut. This offers particular difficulties at low GVFs and for mass-based instrumentation.

For example, consider a mixture of pure water and gas, where the water density is taken as $1000 \mathrm{~kg} / \mathrm{m} 3$, the gas density at line temperature and pressure is $5 \mathrm{~kg} / \mathrm{m} 3$, and the GVF is $5 \%$. Then in every cubic meter of gas/liquid mixture, there are $950 \mathrm{~kg}$ of water, and only $250 \mathrm{~g}$ of gas; the GOST standard requires the latter is to be measured to within $\pm 12.5 \mathrm{~g}$. To achieve such a resolution for the gas which is dispersed within $950 \mathrm{~kg}$ of water is an extremely challenging requirement. Nevertheless, this performance has been broadly achieved in the tests carried out at TUV-NEL.

Figure 11 shows the Skid positioned in the three-phase test facility at TUV-NEL. The separator system provides water and oil streams, while a liquid nitrogen store is used to supply the test gas. Each phase is metered separately, before being combined and passed through the skid. As the flow ranges of the individual phases were less than the calibrated ranges of the standard volumetric reference meters used at TUV-NEL, 
additional mass flow meters were employed. These were calibrated at TUV-NEL, and a detailed uncertainty analysis was provided at each test point, as discussed below. For each experiment performed, steady conditions were established for the desired oil, water and gas flow rates, and then the reference single phase measurements was compared with the outputs of the Skid averaged over a fixed duration. During the modelbuilding stage the duration was 120s, but for the final tests a 300s duration was used, the minimum advised by NEL for formal trials. During the formal trials the operating pressure at the Skid inlet was typically 350 $\mathrm{kPa}$, while the operating temperature ranged between $35^{\circ} \mathrm{C}$ and $44^{\circ} \mathrm{C}$.

The test matrix is shown in Figures 12 and 13. A total of 75 tests were carried out, mostly at intermediary flow rates between the modelling data points. Figure 12 shows the nominal GVF and mass flow rates used for each test; in practice, the recorded values varied within a few percent from the nominal, due to the limited accuracy of the experimental flow control. The total (water + oil) liquid mass flow rates range from $11 \mathrm{~kg} / \mathrm{s}$ down to $2.3 \mathrm{~kg} / \mathrm{s}$. The maximum GVF decreases as the liquid mass flow rate increases, reflecting a practical limitation on the pressure drop across the Skid of approximately $1.5 b a r$. Figure 13 shows the mass flow and water cut values used for the tests. Water cuts were tested in steps of $10 \%$ between $10 \%$ and $90 \%$, with further tests at 2\%, 5\%, 95\% and 98\% water cuts. Tests on pure water or pure oil were not possible given the low levels of cross-contamination in the water and oil supplies from TUV-NEL's separator system. This cross-contamination was, however, monitored and included in the calculation of Skid errors and system uncertainties.

Particular care has been taken over the uncertainty of the reference measurement system, which proved to be a challenging aspect of the trial. Given the wide range of flow rates, GVFs and water cuts, and the relatively small size $(50 \mathrm{~mm})$ of the Skid, TUV-NEL's conventional reference meters were unable to cover the full range of flows required, and so mass flow meters were used to monitor the single phase gas, water and oil streams. Each of these alternative reference meters were calibrated against the National Flow Standard at TUV-NEL prior to use in the trial. The uncertainty of each of the reference measurements varies with test points, and was calculated by TUV-NEL. In all cases, expanded uncertainties are given, based on a standard 
uncertainty multiplied by a coverage factor $\mathrm{k}=2$. Table 1 lists the maximum and minimum values and corresponding relative uncertainties of the key reference measurements. The turndown required for the total liquid mass flow rate (i.e. the ratio of maximum to minimum flow rate) is relatively small - a factor of just over 4:1 - and accordingly the uncertainty range for this reference measurement is relatively steady, varying between $0.4 \%$ and $0.6 \%$. Similarly, the water cut and GVF uncertainties are relatively steady. However, the turn-down ratios of the individual gas water and oil flow rates are much higher - over 500:1 in the case of the water flow rate - and so at the lowest water flow rate of $0.01 \mathrm{~kg} / \mathrm{s}$, the uncertainty is $63 \%$. Note that in all test cases the uncertainties of the reference measurements are less than the target accuracy, and in most cases by a healthy margin. Specifically, for the total liquid mass flow rate, where the target accuracy is $\pm 2.5 \%$, the maximum reference uncertainty is $0.6 \%$ as shown in Table 1 . For the gas flow rate, where the target accuracy is $\pm 5.0 \%$, the maximum reference uncertainty shown in Table 1 is $4.3 \%$, but as detailed in NEL's report, in only three cases does the reference uncertainty exceed $2.5 \%$. For the oil flow rate, the maximum reference uncertainty is 35\%, but this occurs at high water cut (98\%) where there is no target accuracy. For water cuts where a target accuracy is defined (95\% water cut or less), the largest reference uncertainty is accuracy is $6.1 \%$ at $90 \%$ water cut, where the target accuracy is $15 \%$.

Figures 14 - 18 give a summary of the results obtained in these test trials. Figure 14 shows the total liquid flow errors against water cut. The total liquid flow performance is similar across all water cuts, $97 \%$ of the points fall within the GOST specification of $\pm 2.5 \%$, and all points fall within $\pm 4 \%$. Figure 15 shows the same results presented as a probability distribution, i.e. the percentage of test points having an absolute error in the liquid mass flow reading of less than a certain value. Thus $66 \%$ of the test points have an error of less than $\pm 1 \%$, and $85 \%$ of the test points have an error of less than $\pm 1.5 \%$.

The results and probability distribution for the gas mass flow rate are shown in Figure 16 and 17. Again the results fall substantially within the GOST specification, with $93 \%$ of the test points falling within the $\pm 5 \%$ limit. As discussed above, the GOST standard specifies a maximum oil error which varies with water cut. For water cuts below $70 \%$, the permitted oil mass flow error is $\pm 6 \%$; between $70 \%$ and $95 \%$ water cut, the 
oil mass flow error limit is $\pm 15 \%$; and above $95 \%$ water cut, no oil mass flow error limit is specified. As shown in Figure 18, all test points match this performance requirement. No probability plot is shown as the error requirement is not constant across all experiments.

Finally, table 2 provides the complete set of results for all 75 tests, giving the reference measurements and Skid errors for the oil, water, gas and total liquid flow rates.

\section{DISCUSSION}

This paper has described a new commercial three-phase metering system based on Coriolis mass flow metering combined with water cut metering. The results from laboratory trials suggest that this technology has promise for applications in the oil and gas industry. Further formal lab trials are taking place on different sized Skids. However, three-phase metering is a notoriously complex problem, and we anticipate further technical challenges arising as field trial experience is acquired.

Specifically, it is important to determine for what range of parameters (particularly pressure, temperature and fluid properties e.g. oil viscosity, the velocity of sound) a model proved in a flow laboratory can provide good performance in the field. Early field experience suggests that both the water cut and Coriolis meter models will require field tuning: the techniques needed to do so will emerge in time. More generally, it is desirable to reduce the empirical nature of the correction models by quantifying as far as possible the influence of physical parameters (for example as discussed in the literature discussed above ([7-15]); hopefully the most influential factors will emerge through further experimental and field experience.

To a large extent, the current limit of $50 \%$ GVF is set by the communication speed of the Modbus communication protocol, together with the observed pattern of flow. Rapid slugs of (say) less than two seconds duration are difficult to measure accurately with only a $1 \mathrm{~Hz}$ update rate. The Coriolis meter at least is generating measurement data at a much higher rate (typically at $160 \mathrm{~Hz}$ ), and with higher communication and computation bandwidth, accurate tracking of higher GVF multiphase flows may become possible. 
While combining Coriolis meter and water cut meter has generated good measurement performance in this paper, it is possible that other technology combinations may be advantageous, and will be the subject of future research. Of particular benefit would be a means of detecting and measuring slip between the gas and liquid phases, which could lead to significant improvement in the understanding and exploitation of this technology. 


\section{Nomenclature}

$\alpha_{c} \quad$ gas volume fraction based on corrected data (\%)

$\rho_{g} \quad$ gas density at local temperature and pressure $\left(\mathrm{kg} / \mathrm{m}^{3}\right)$

$\rho_{o} \quad$ oil density at local temperature and pressure $\left(\mathrm{kg} / \mathrm{m}^{3}\right)$

$\rho_{w} \quad$ water density at local temperature and pressure $\left(\mathrm{kg} / \mathrm{m}^{3}\right)$

$\rho_{l} \quad$ liquid only (oil and water) mixture density at local temperature and pressure $\left(\mathrm{kg} / \mathrm{m}^{3}\right)$

$\rho_{m a} \quad$ apparent mixture density from the Coriolis mass flow meter $\left(\mathrm{kg} / \mathrm{m}^{3}\right)$

$\rho_{m c} \quad$ corrected mixture density from the Coriolis mass flow meter $\left(\mathrm{kg} / \mathrm{m}^{3}\right)$

dd $\quad$ difference between the liquid-only mixture density $\rho_{l}$ and the observed density $\rho_{m a}(\%)$

$\dot{m}_{g} \quad$ mass flow rate of gas $(\mathrm{kg} / \mathrm{s})$

$\dot{m}_{l} \quad$ mass flow rate of liquid $(\mathrm{kg} / \mathrm{s})$

$\dot{m}_{o} \quad$ mass flow rate of oil $(\mathrm{kg} / \mathrm{s})$

$\dot{m}_{w} \quad$ mass flow rate of water $(\mathrm{kg} / \mathrm{s})$

$\dot{m}_{m a} \quad$ apparent three-phase mixture mass flow rate from the Coriolis mass flow meter (kg/s)

$\dot{m}_{m c} \quad$ corrected three-phase mixture mass flow rate from the Coriolis mass flow meter (kg/s)

$P \quad$ the absolute pressure at the inlet to the Coriolis mass flow meter $(\mathrm{kPa})$,

$T \quad$ the process fluid temperature from the RTD sensor $(\mathrm{K})$

wc the water cut from the water cut meter, after any correction (\%) 


\section{Figure Captions}

\section{Figure 1: Net Oil Skid Design}

Figure 2: Hardware/Software Architecture of Net Oil and Gas System

Figure 3: 50mm Coriolis Meter Mass Flow Errors vs. GVF and Water Cut for true mass flow rate $6.3 \mathrm{~kg} / \mathrm{s}$. Figure 4: 50mm Coriolis Meter Density Errors vs. GVF and Water Cut for true mass flow rate $6.3 \mathrm{~kg} / \mathrm{s}$.

Figure 5: 50mm Coriolis Meter Mass Flow Errors vs. GVF and Water Cut for true mass flow rate $4.0 \mathrm{~kg} / \mathrm{s}$. Figure 6: 50mm Coriolis Meter Density Errors vs. GVF and Water Cut for true mass flow rate $4.0 \mathrm{~kg} / \mathrm{s}$.

Figure 7: 50mm Coriolis Meter Mass Flow Errors vs. density drop and Water Cut for true mass flow rate 6.3 $\mathrm{kg} / \mathrm{s}$.

Figure 8: 50mm Coriolis Meter Density Errors vs. density drop and Water Cut for true mass flow rate $6.3 \mathrm{~kg} / \mathrm{s}$. Figure 9: 50mm Coriolis Meter Mass Flow Errors vs. density drop and Water Cut for true mass flow rate 4.0 $\mathrm{kg} / \mathrm{s}$.

Figure 10: 50mm Coriolis Meter Density Errors vs. density drop and Water Cut for true mass flow rate $4.0 \mathrm{~kg} / \mathrm{s}$.

Figure 11: Experimental setup: Net Oil \& Gas Skid at TUV-NEL three phase test facility.

Figure 12: Experimental grid - mass flow rate vs. GVF.

Figure 13: Experimental grid - liquid mass flow rate vs. water cut.

Figure 14: Total liquid mass flow rate errors against water cut. The target limit is $\pm 2.5 \%$ (red boundary).

Figure 15: Total Liquid Error probability distribution.

Figure 16: Gas mass flow error against gas volume fraction. The target limit is $\pm 5 \%$ (red boundary).

Figure 17: Gas mass flow error probability distribution.

Figure 18: Oil mass flow error against water cut. The target performance (red boundary) is $\pm 6.0 \%$ for water cuts less than $70 \%, \pm 15.0 \%$ for water cuts between $70 \%$ and $95 \%$. 


\section{Figures}
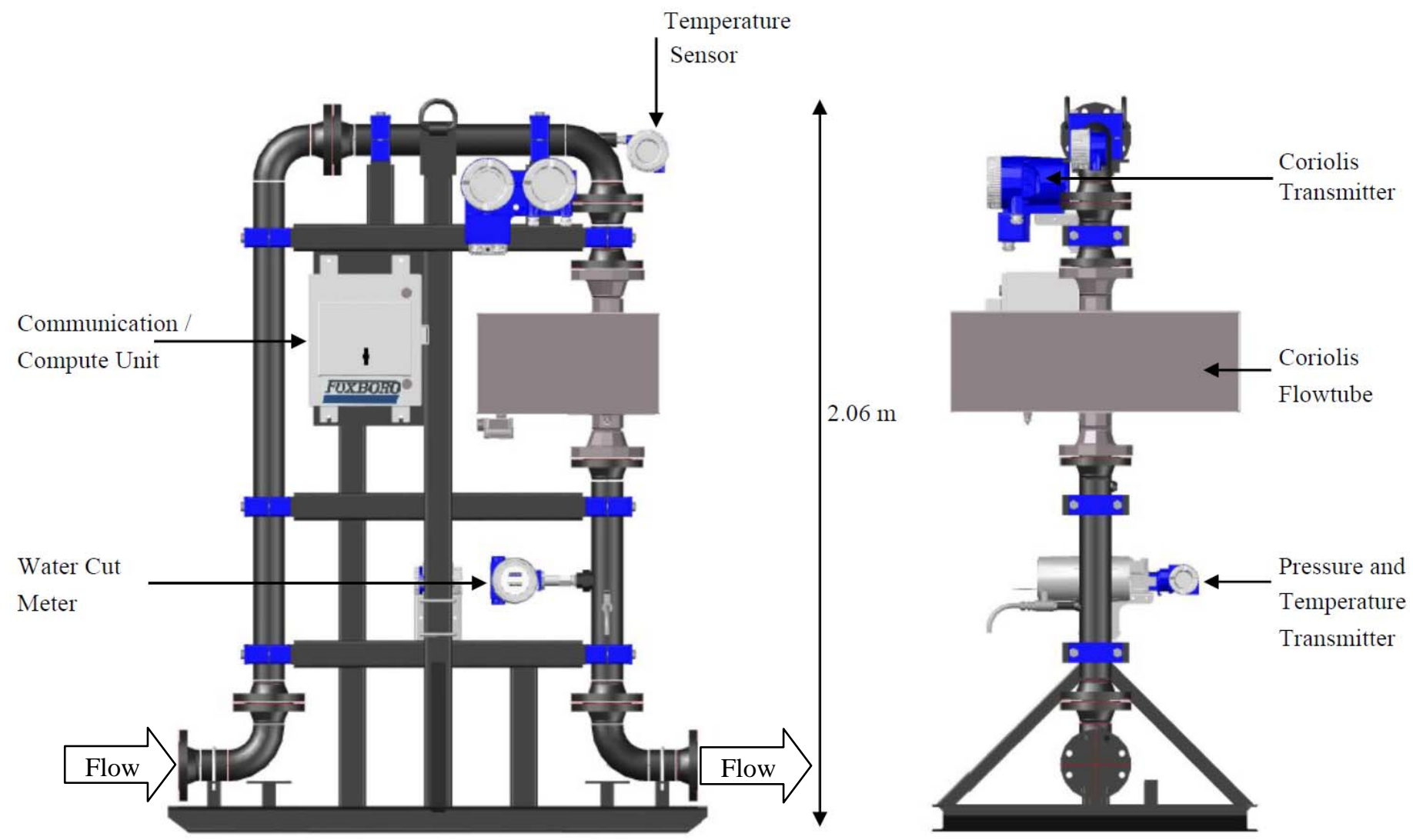

Figure 1: Net Oil Skid Design 


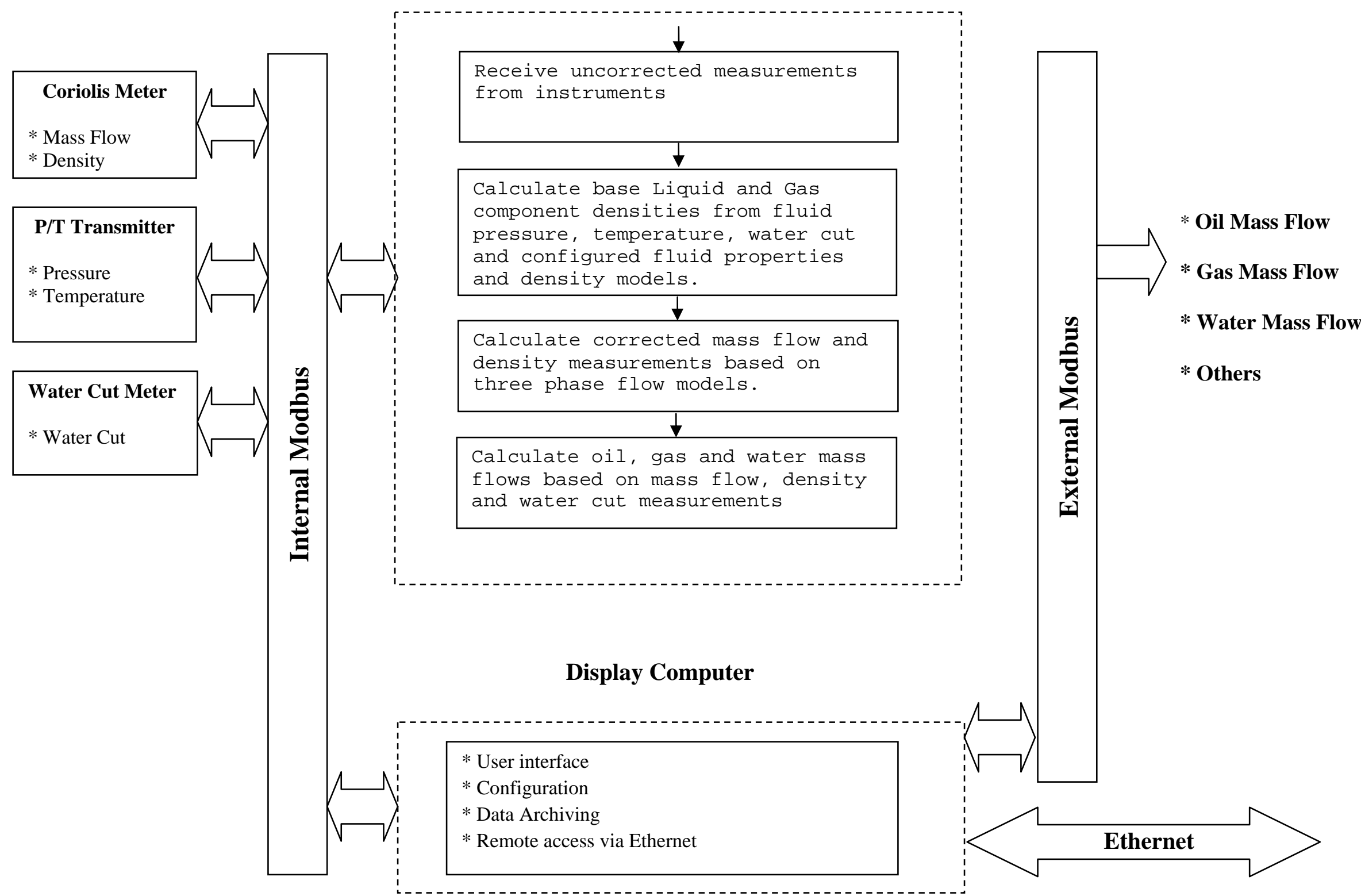

Figure 2: Hardware/Software Architecture of Net Oil and Gas System 


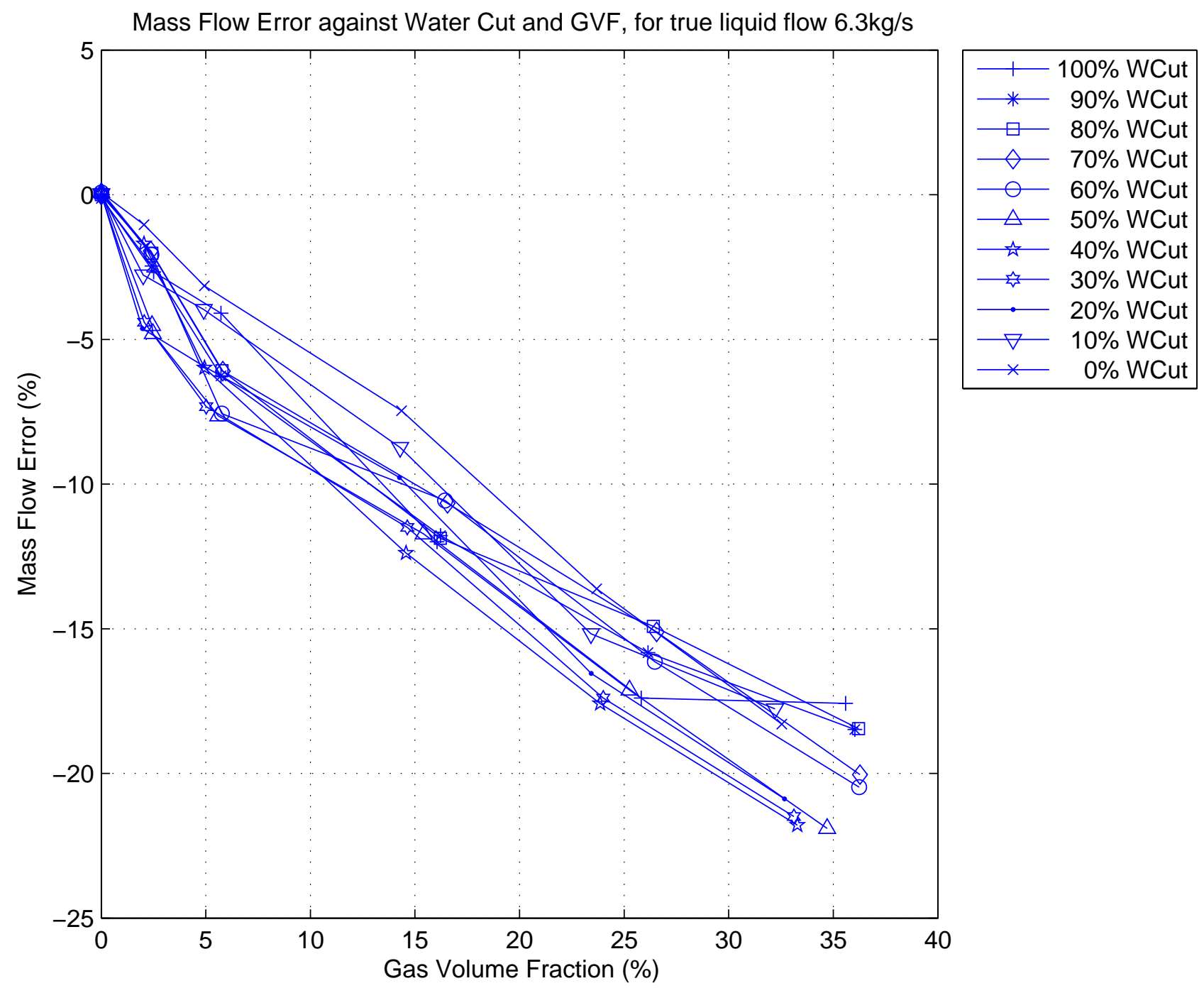

Figure 3: 50mm Coriolis Meter Mass Flow Errors vs. GVF and Water Cut for true mass flow rate 6.3 kg/s. 


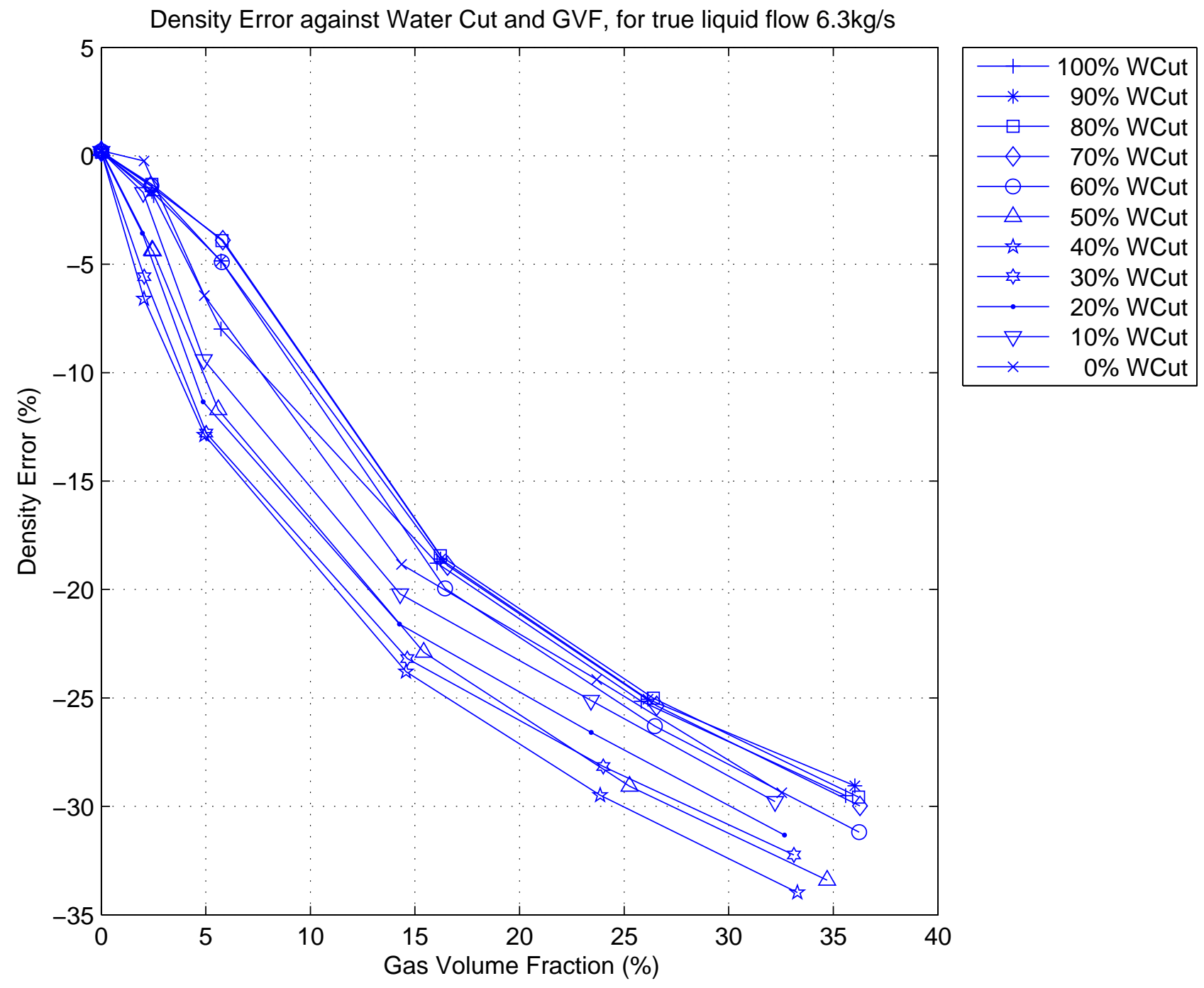

Figure 4: 50mm Coriolis Meter Density Errors vs. GVF and Water Cut for true mass flow rate $6.3 \mathrm{~kg} / \mathrm{s}$. 


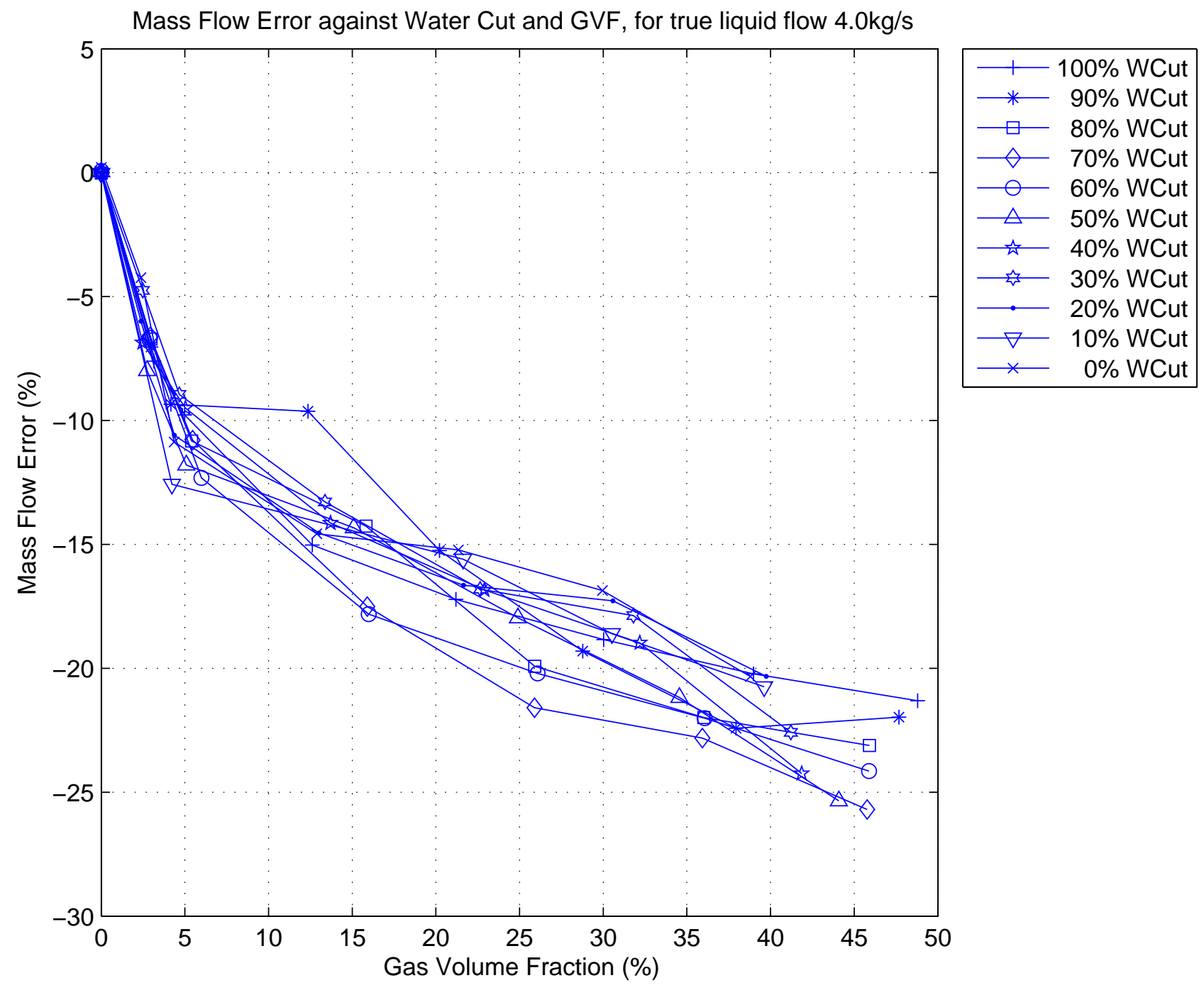

Figure 5: 50mm Coriolis Meter Mass Flow Errors vs. GVF and Water Cut for true mass flow rate $4.0 \mathrm{~kg} / \mathrm{s}$. 


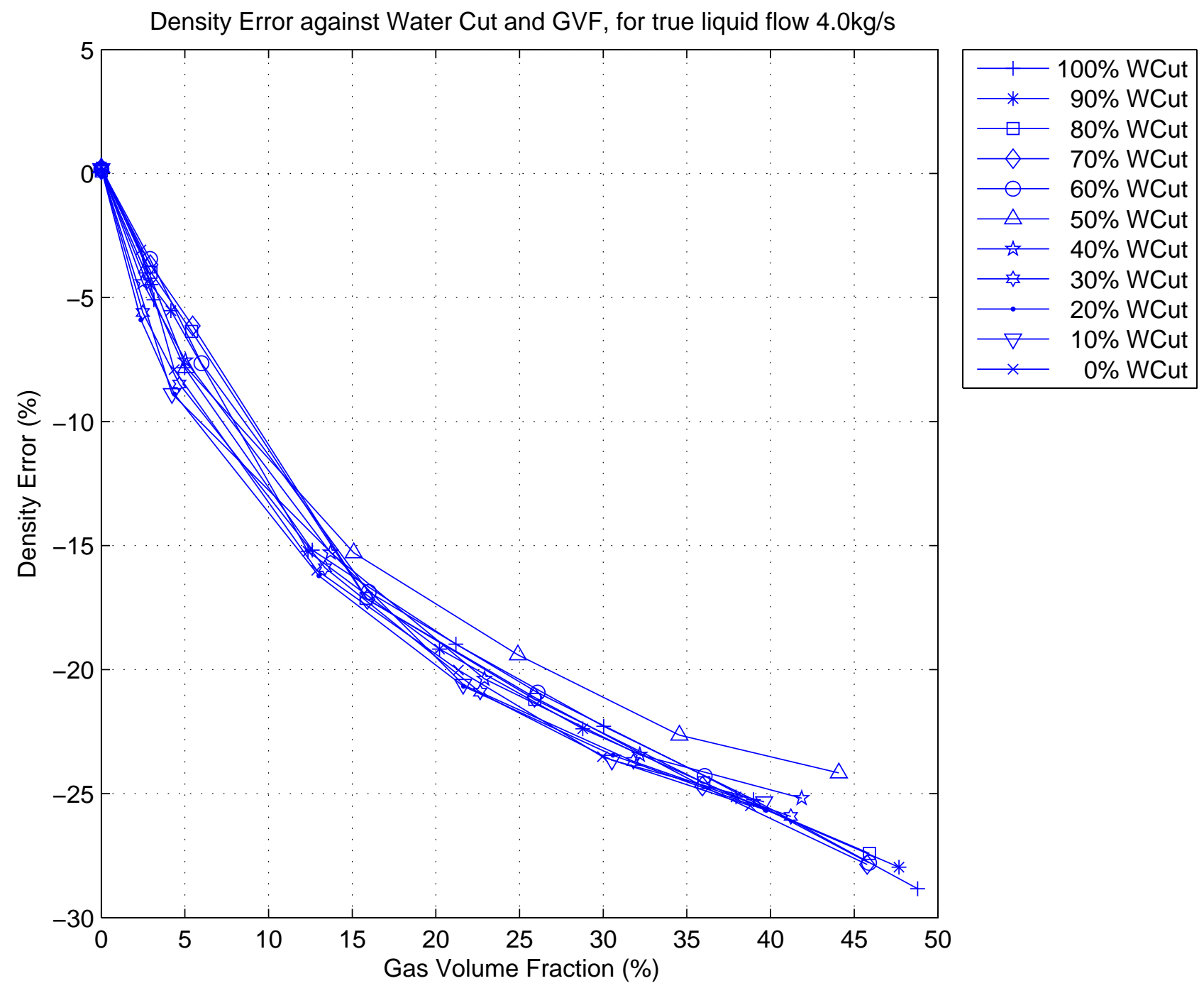

Figure 6: 50mm Coriolis Meter Density Errors vs. GVF and Water Cut for true mass flow rate $4.0 \mathrm{~kg} / \mathrm{s}$. 
Mass Flow Error against Water Cut and Density Drop, for true liquid flow 6.3kg/s

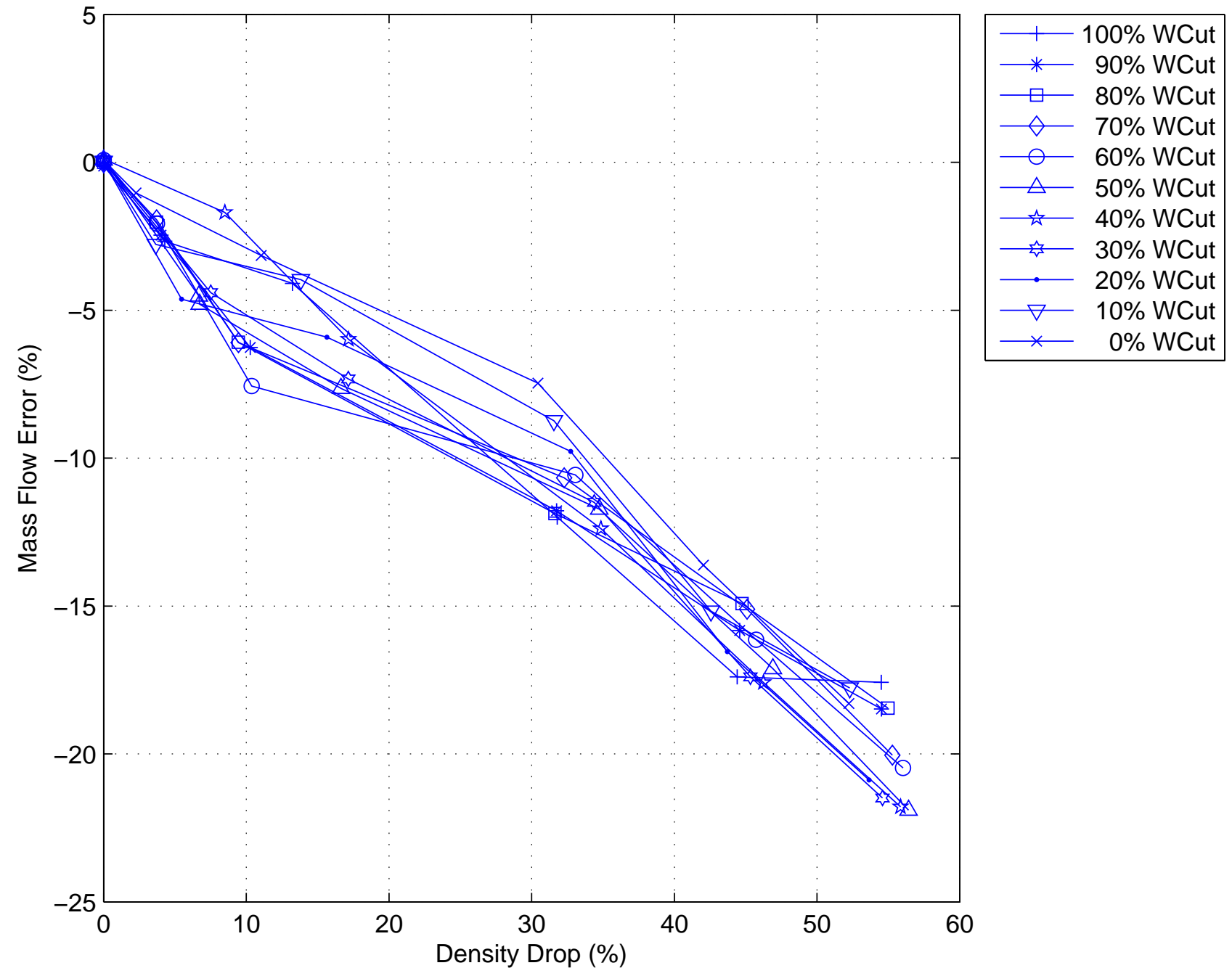

Figure 7: 50mm Coriolis Meter Mass Flow Errors vs. density drop and Water Cut for true mass flow rate 6.3 $\mathrm{kg} / \mathrm{s}$. 


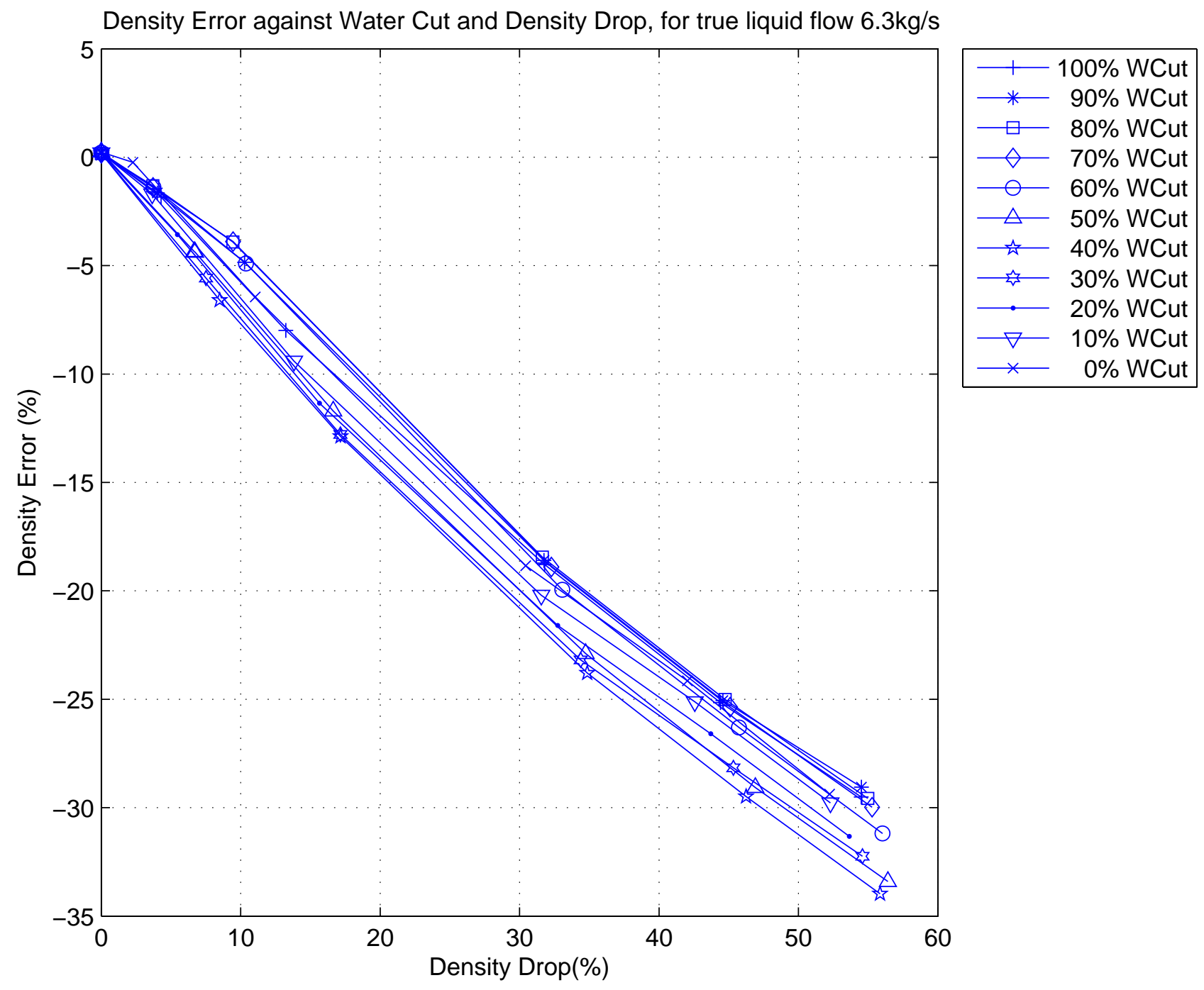

Figure 8: 50mm Coriolis Meter Density Errors vs. density drop and Water Cut for true mass flow rate $6.3 \mathrm{~kg} / \mathrm{s}$. 
Mass Flow Error against Water Cut and Density Drop, for true liquid flow 4.0kg/s

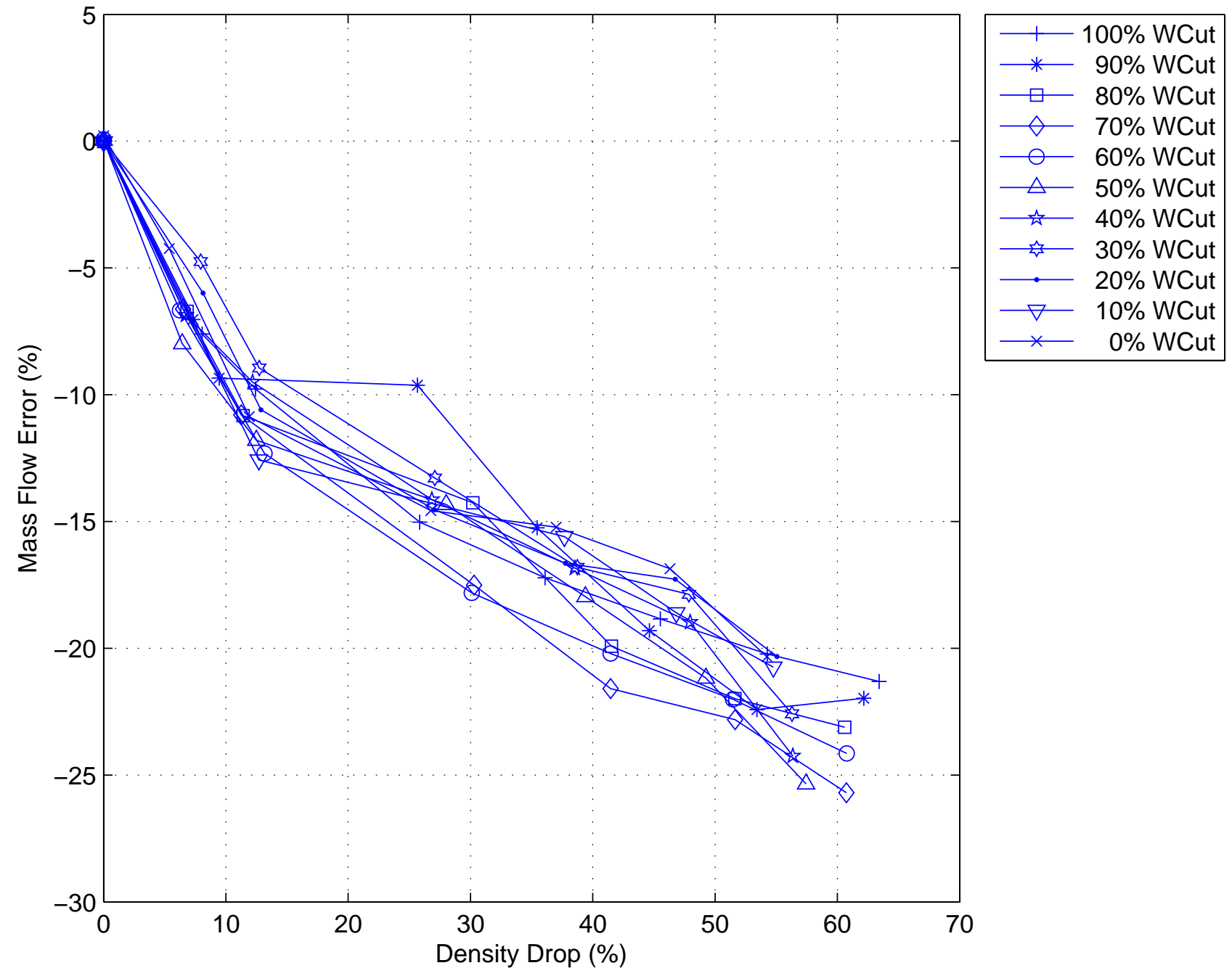

Figure 9: 50mm Coriolis Meter Mass Flow Errors vs. density drop and Water Cut for true mass flow rate 4.0 $\mathrm{kg} / \mathrm{s}$. 


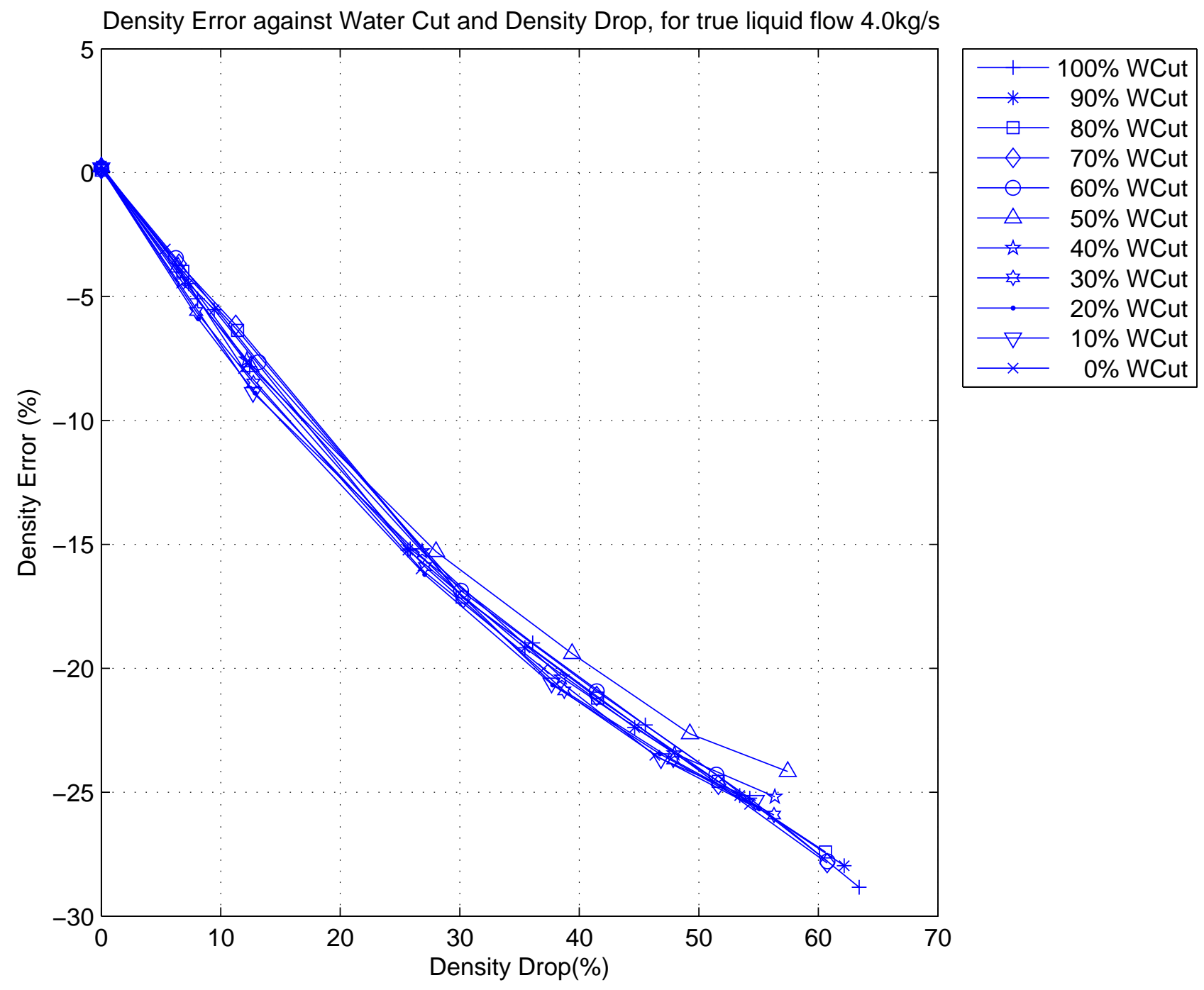

Figure 10: 50mm Coriolis Meter Density Errors vs. density drop and Water Cut for true mass flow rate $4.0 \mathrm{~kg} / \mathrm{s}$. 
Three-phase separator

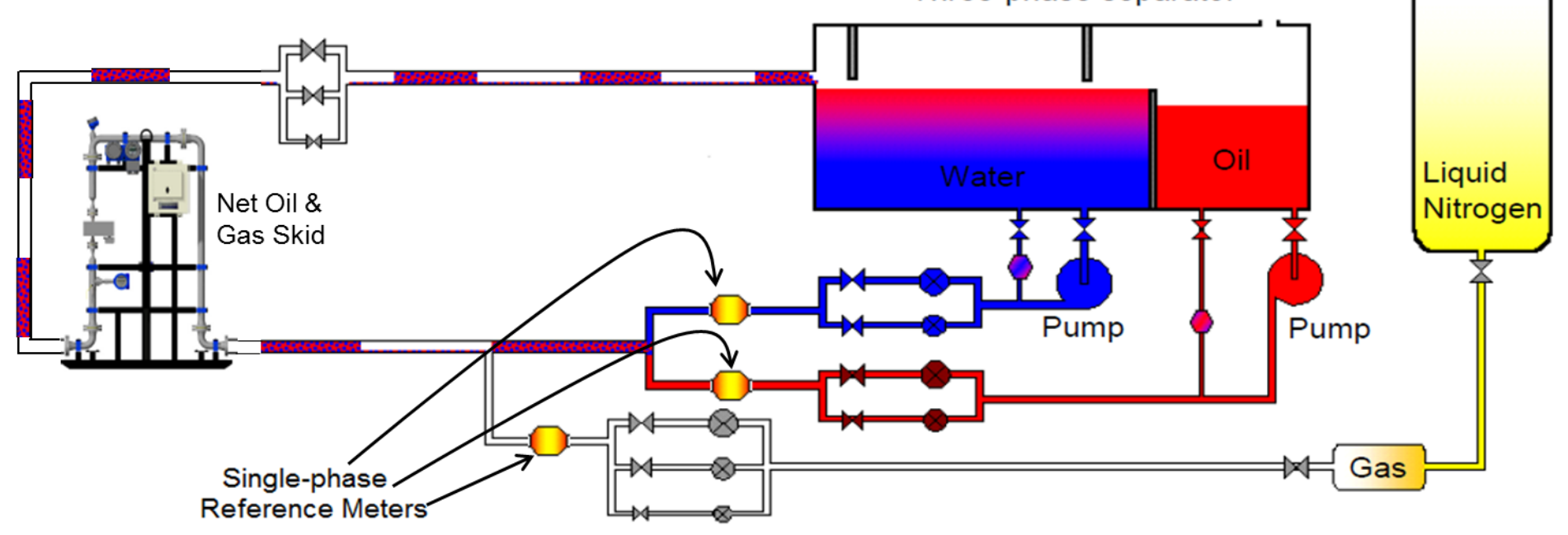

Figure 11: Experimental setup: Net Oil \& Gas Skid at TUV-NEL three phase test facility. 


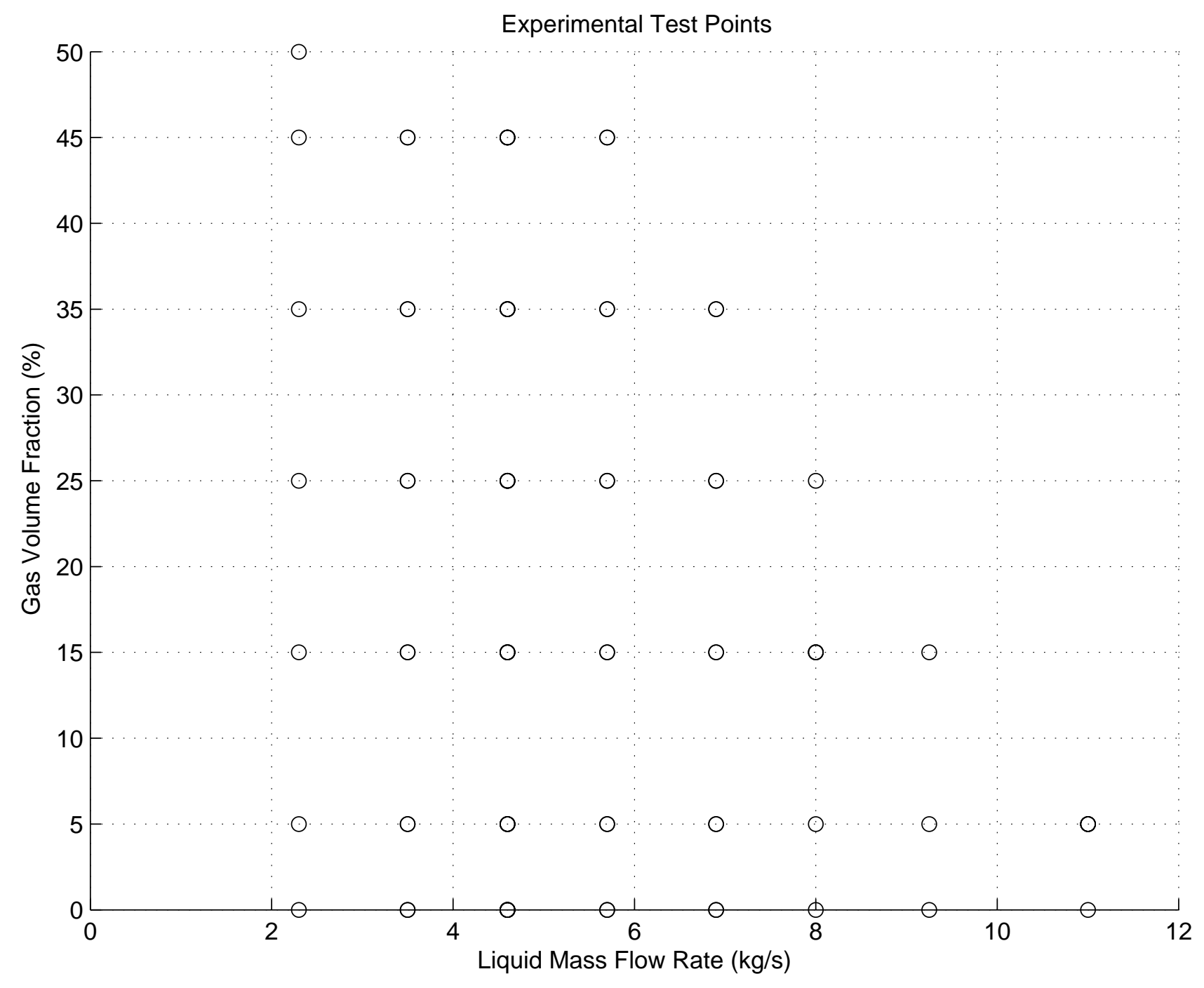

Figure 12: Experimental grid - mass flow rate vs. GVF. 


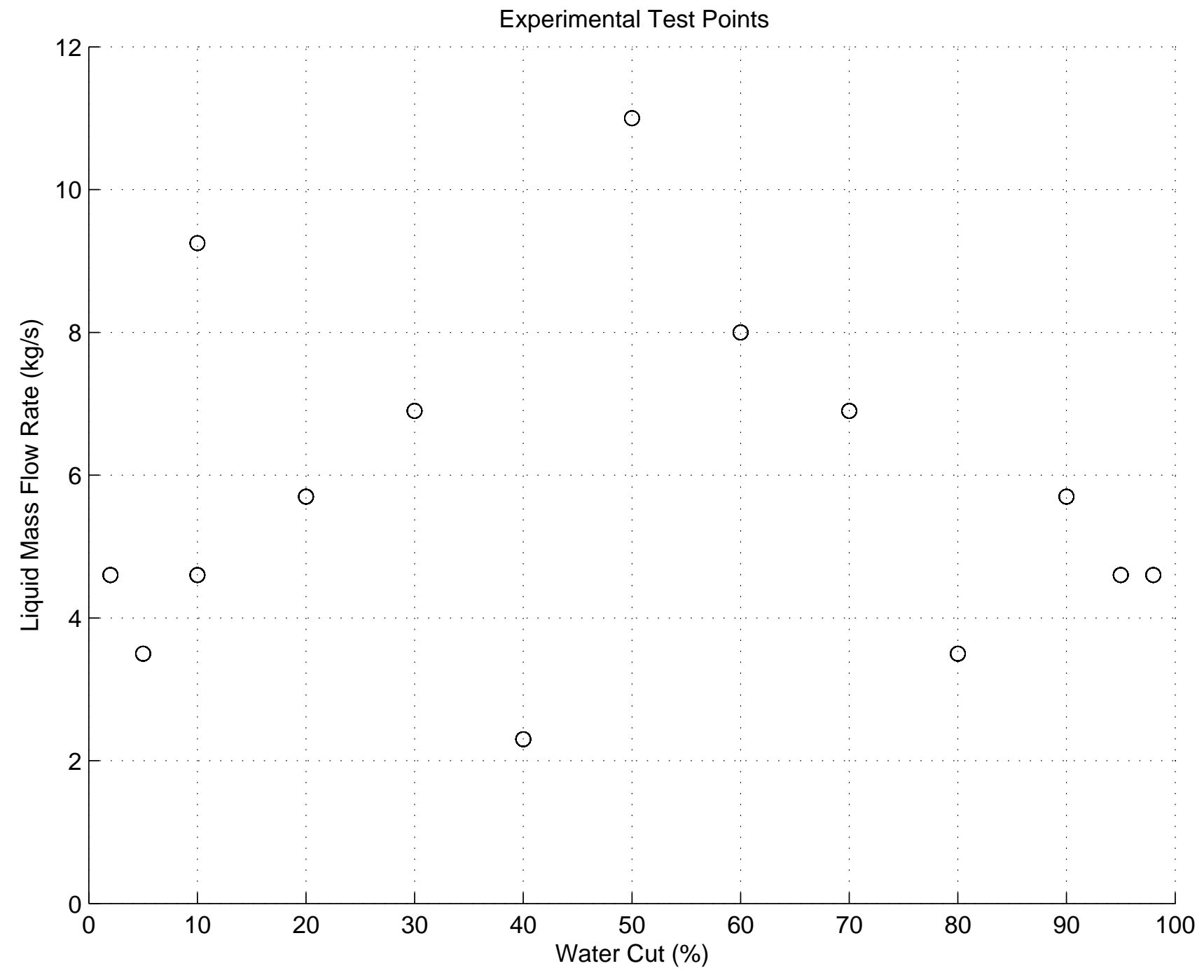

Figure 13: Experimental grid - liquid mass flow rate vs. water cut. 


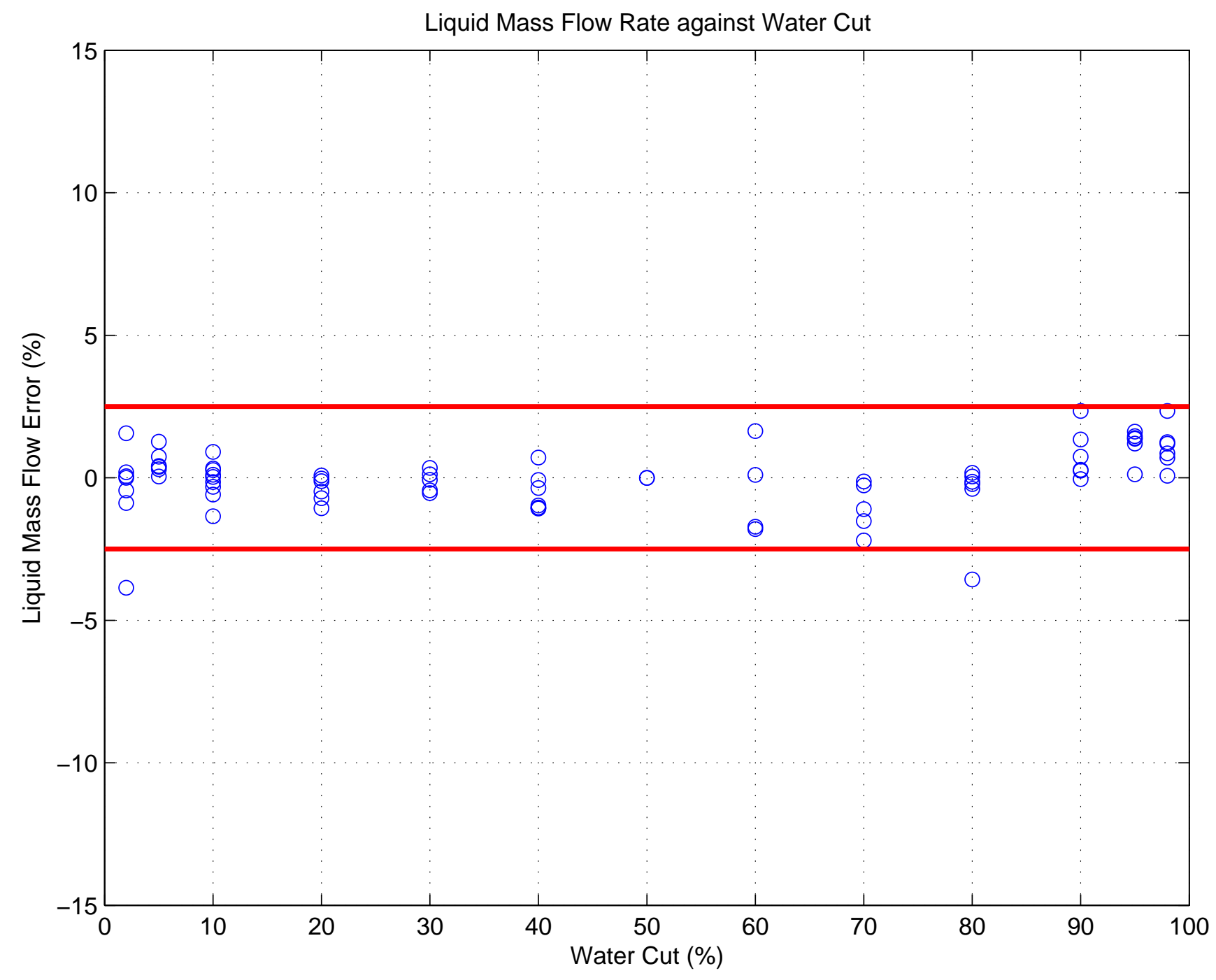

Figure 14: Total liquid mass flow rate errors against water cut. The target limit is $\pm 2.5 \%$ (red boundary). 


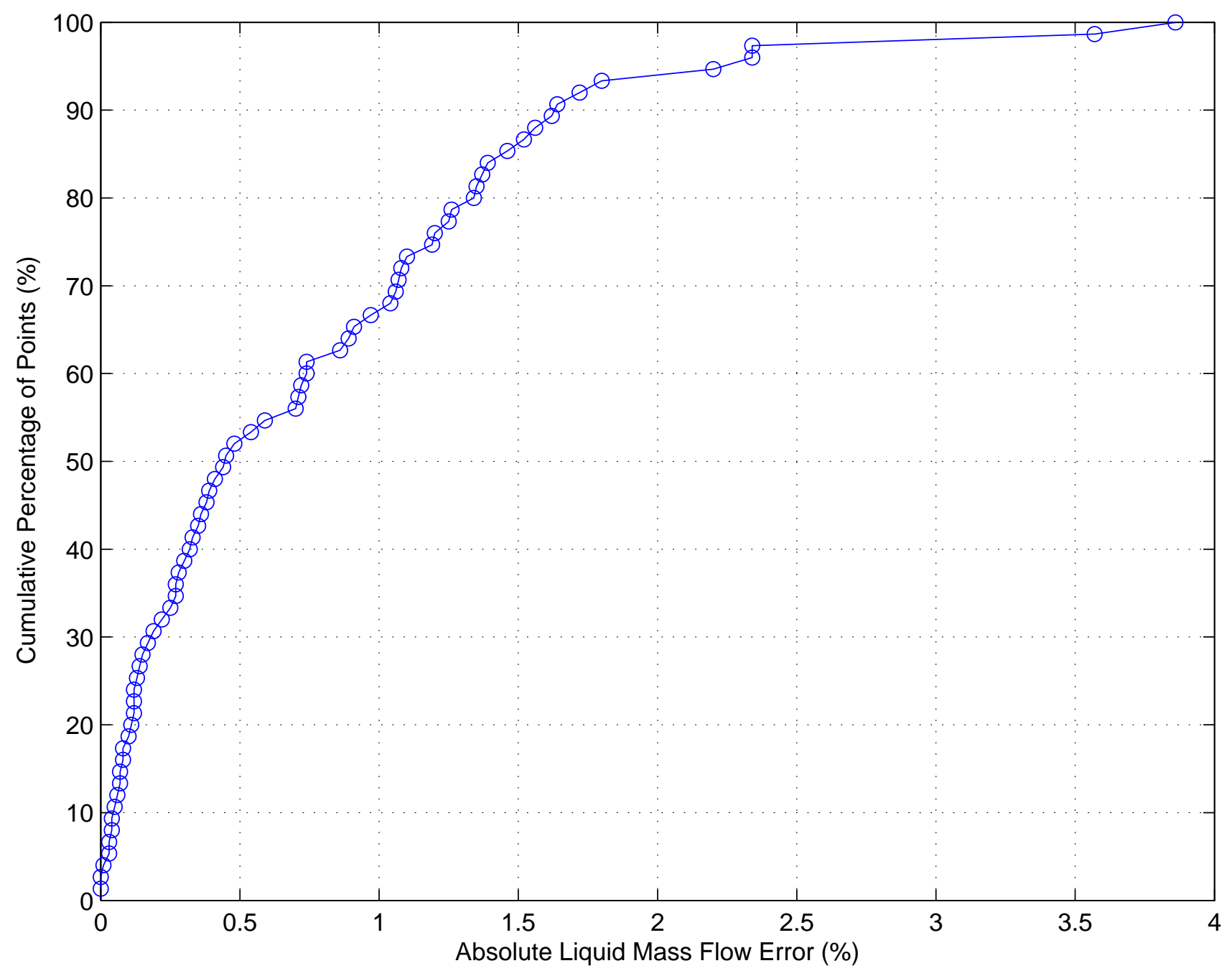

Figure 15: Total Liquid Error probability distribution. 


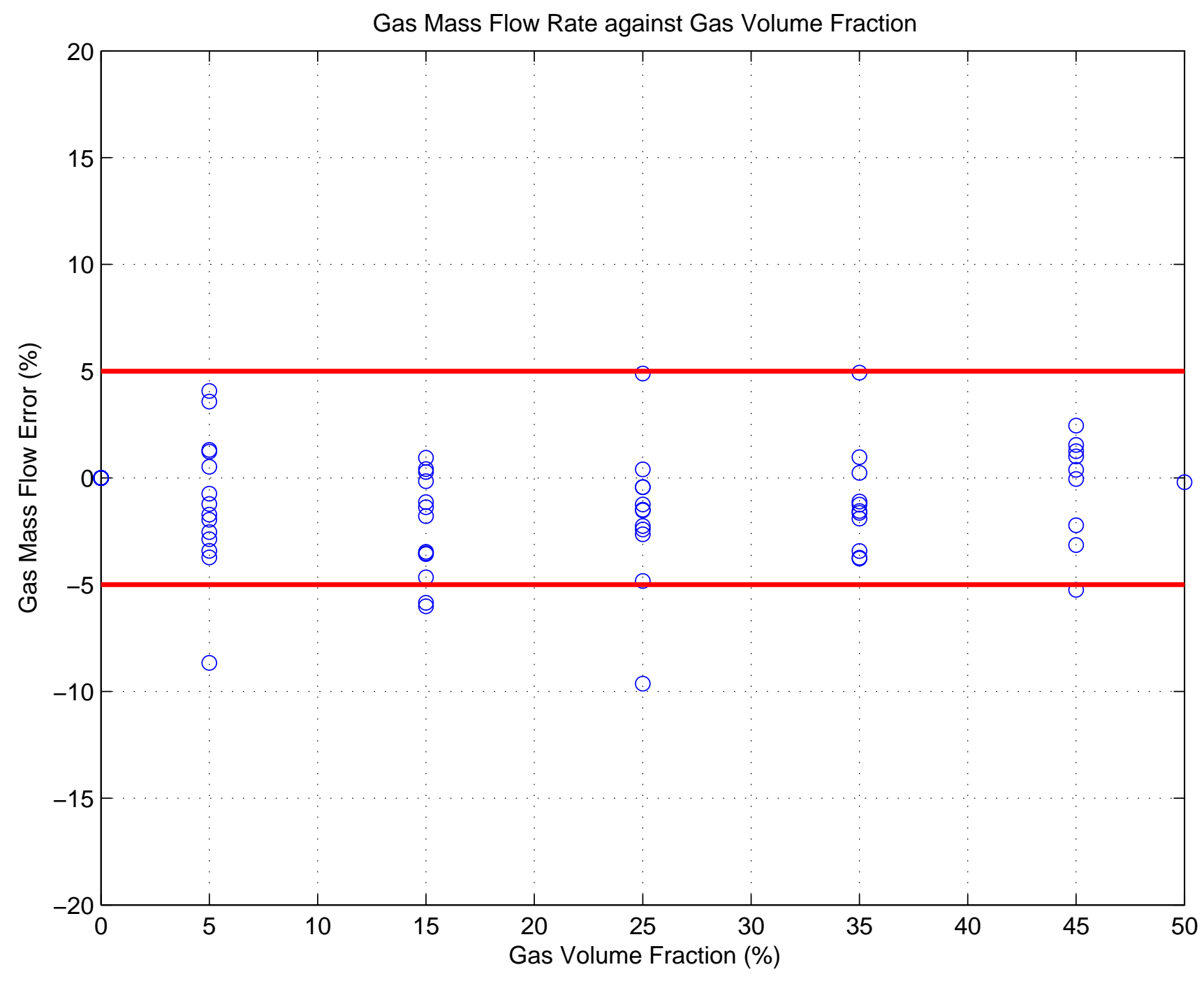

Figure 16: Gas mass flow error against gas volume fraction. The target limit is $\pm 5 \%$ (red boundary). 


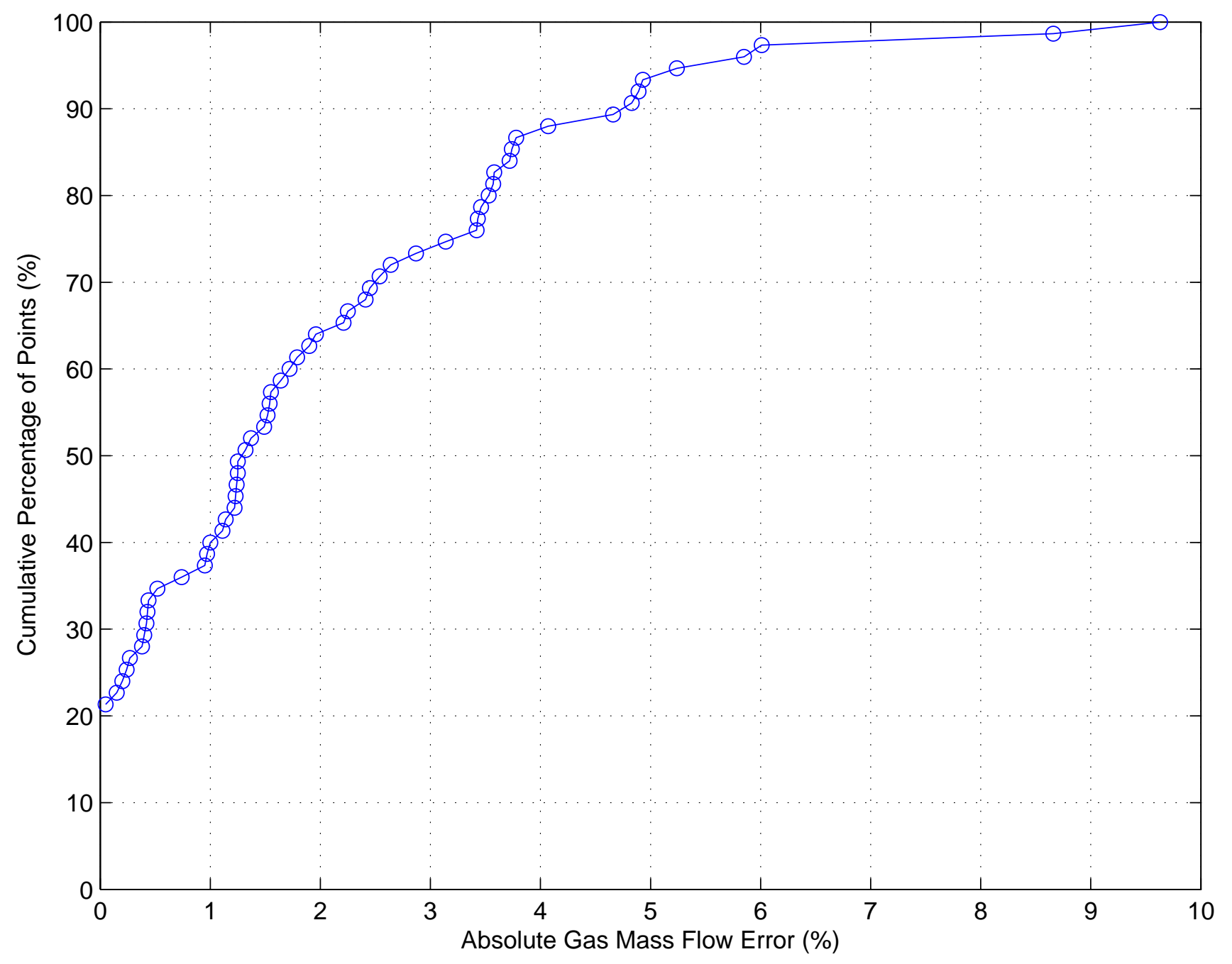

Figure 17: Gas mass flow error probability distribution. 


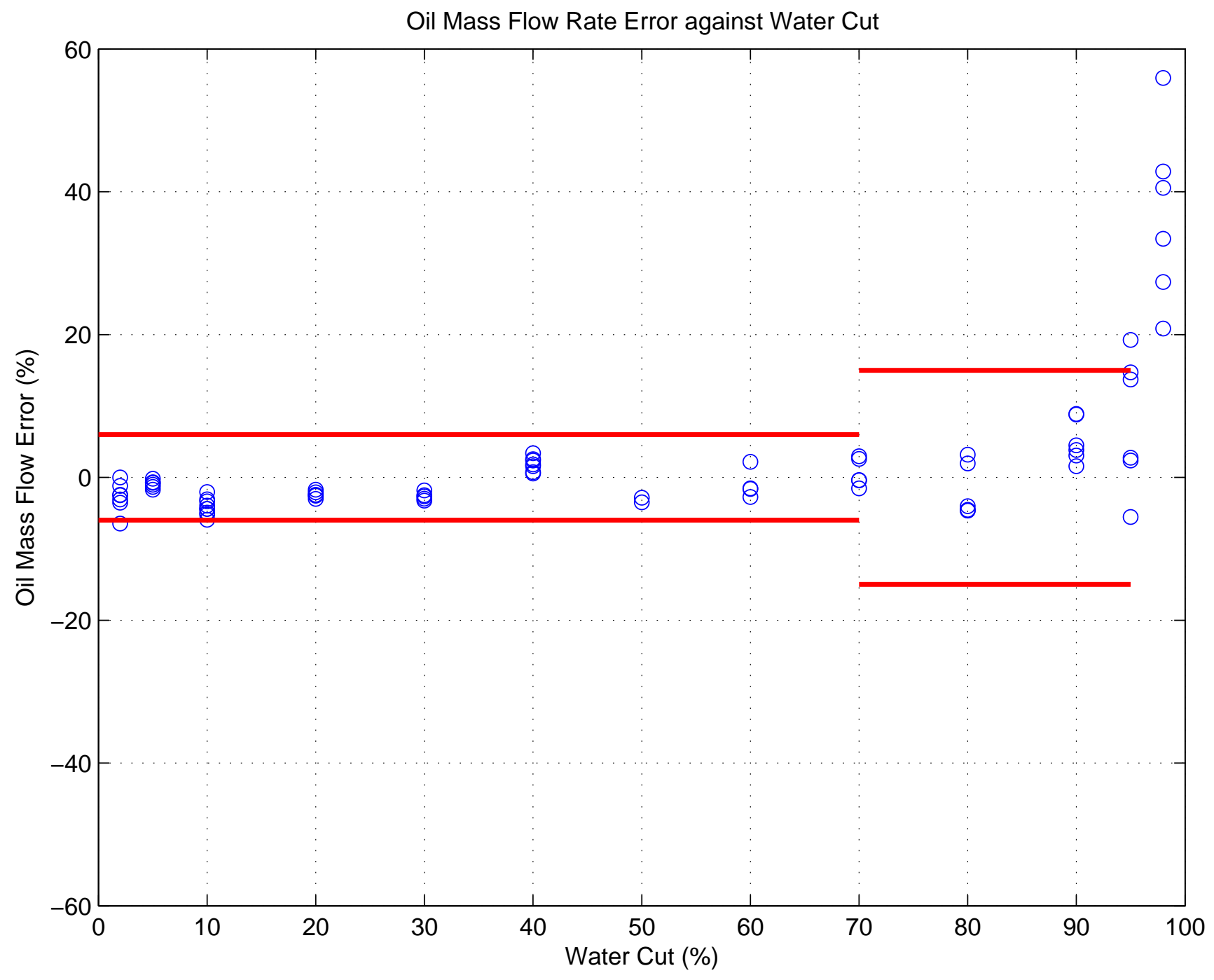

Figure 18: Oil mass flow error against water cut. The target performance (red boundary) is $\pm 6.0 \%$ for water cuts less than $70 \%, \pm 15.0 \%$ for water cuts between $70 \%$ and $95 \%$. 
Table 1: Maximum and Minimum Reference Measurement Uncertainties for TUV-NEL trials. The measurements shown exclude zero values for water cut, GVF, gas, oil and water to avoid arbitrarily large relative uncertainties. The uncertainties shown are the maximum and minimum values for the entire set of test points.

\begin{tabular}{|c|c|c|c|c|}
\hline \multirow{2}{*}{ Reference Measurement } & \multicolumn{2}{|c|}{ Measurement } & \multicolumn{2}{|c|}{ Uncertainty } \\
\hline & Min & Max & Min & Max \\
\hline Total liquid mass flow rate & $2.5 \mathrm{~kg} / \mathrm{s}$ & $11.6 \mathrm{~kg} / \mathrm{s}$ & $0.4 \%$ & $0.6 \%$ \\
\hline Water Cut & $0.2 \%$ & $98 \%$ & $0.2 \%$ & $0.6 \%$ \\
\hline Gas Volume Fraction & $4.2 \%$ & $48 \%$ & $0.1 \%$ & $0.9 \%$ \\
\hline Gas flow rate & $0.13 \mathrm{~g} / \mathrm{s}$ & $4.4 \mathrm{~g} / \mathrm{s}$ & $1.0 \%$ & $4.3 \%$ \\
\hline Oil flow rate & $0.07 \mathrm{~kg} / \mathrm{s}$ & $9.8 \mathrm{~kg} / \mathrm{s}$ & $0.6 \%$ & $35 \%$ \\
\hline Water flow rate & $0.01 \mathrm{~kg} / \mathrm{s}$ & $5.7 \mathrm{~kg} / \mathrm{s}$ & $0.8 \%$ & $63 \%$ \\
\hline
\end{tabular}


Table 2: Trial results of Net Oil \& Gas Skid at TUV-NEL.

\begin{tabular}{|c|c|c|c|c|c|c|c|c|c|c|c|}
\hline \multirow[b]{2}{*}{ Tag } & \multicolumn{3}{|c|}{ Nominal Experimental Conditions } & \multicolumn{2}{|c|}{ Oil Mass Flow } & \multicolumn{2}{|c|}{ Gas Mass Flow } & \multicolumn{2}{|c|}{ Water Mass Flow } & \multicolumn{2}{|c|}{ Liquid Mass Flow } \\
\hline & $\begin{array}{l}\text { Liq Mflow } \\
(\mathrm{kg} / \mathrm{s})\end{array}$ & $\begin{array}{c}\text { Water Cut } \\
\text { (\%) }\end{array}$ & $\begin{array}{l}\text { GVF } \\
(\%)\end{array}$ & $\begin{array}{c}\text { NEL } \\
\text { Reference } \\
(\mathrm{kg} / \mathrm{s})\end{array}$ & $\begin{array}{c}\text { Skid } \\
\text { Error } \\
(\%)\end{array}$ & $\begin{array}{c}\text { NEL } \\
\text { Reference } \\
(\mathrm{g} / \mathrm{s})\end{array}$ & $\begin{array}{l}\text { Skid } \\
\text { Error } \\
(\%)\end{array}$ & $\begin{array}{c}\text { NEL } \\
\text { Reference } \\
(\mathrm{kg} / \mathrm{s})\end{array}$ & $\begin{array}{l}\text { Skid } \\
\text { Error } \\
(\%)\end{array}$ & $\begin{array}{c}\text { NEL } \\
\text { Reference } \\
(\mathrm{kg} / \mathrm{s})\end{array}$ & $\begin{array}{l}\text { Skid } \\
\text { Error } \\
(\%)\end{array}$ \\
\hline $2-40-\mathrm{F}$ & 2.30 & 40.0 & 0.0 & 1.2861 & $1.55 \%$ & 0.0000 & $0.00 \%$ & 1.0145 & $-2.15 \%$ & 2.3005 & $-0.08 \%$ \\
\hline $2-40-Z$ & 2.30 & 40.0 & 50.0 & 1.2894 & $2.56 \%$ & 9.5630 & $-0.20 \%$ & 1.0343 & $-5.62 \%$ & 2.3237 & $-1.08 \%$ \\
\hline $2-40-A$ & 2.30 & 40.0 & 45.0 & 1.2753 & $3.38 \%$ & 7.8299 & $1.54 \%$ & 1.0319 & $-4.98 \%$ & 2.3072 & $-0.36 \%$ \\
\hline $2-40-B$ & 2.30 & 40.0 & 35.0 & 1.2724 & $1.81 \%$ & 5.4337 & $0.97 \%$ & 1.0047 & $-4.69 \%$ & 2.2771 & $-1.06 \%$ \\
\hline $2-40-C$ & 2.30 & 40.0 & 25.0 & 1.2925 & $2.37 \%$ & 3.3711 & $-0.44 \%$ & 1.0275 & $-1.38 \%$ & 2.3200 & $0.71 \%$ \\
\hline 2-40-D & 2.30 & 40.0 & 15.0 & 1.2864 & $0.53 \%$ & 1.7127 & $-1.14 \%$ & 1.0190 & $-2.86 \%$ & 2.3054 & $-0.97 \%$ \\
\hline $2-40-E$ & 2.30 & 40.0 & 5.0 & 1.2865 & $0.75 \%$ & 0.4899 & $-3.42 \%$ & 1.0234 & $-3.29 \%$ & 2.3099 & $-1.04 \%$ \\
\hline $3-80-F$ & 3.50 & 80.0 & 0.0 & 0.5935 & $-4.55 \%$ & 0.0000 & $0.00 \%$ & 2.8879 & $0.98 \%$ & 3.4815 & $0.04 \%$ \\
\hline $3-80-A$ & 3.50 & 80.0 & 45.0 & 0.5946 & $1.96 \%$ & 12.2696 & $-5.24 \%$ & 2.8807 & $-4.71 \%$ & 3.4753 & $-3.57 \%$ \\
\hline $3-80-B$ & 3.50 & 80.0 & 35.0 & 0.5942 & $3.18 \%$ & 8.0861 & $-1.64 \%$ & 2.9600 & $-0.81 \%$ & 3.5542 & $-0.14 \%$ \\
\hline $3-80-C$ & 3.50 & 80.0 & 25.0 & 0.5835 & $-4.04 \%$ & 4.4988 & $-0.43 \%$ & 2.8960 & $0.35 \%$ & 3.4795 & $-0.39 \%$ \\
\hline 3-80-D & 3.50 & 80.0 & 15.0 & 0.5974 & $-4.65 \%$ & 2.3827 & $0.95 \%$ & 2.9111 & $1.16 \%$ & 3.5086 & $0.17 \%$ \\
\hline 3-80-E & 3.50 & 80.0 & 5.0 & 0.5867 & $-4.62 \%$ & 0.7672 & $4.07 \%$ & 2.8752 & $0.68 \%$ & 3.4619 & $-0.22 \%$ \\
\hline $3-5-F$ & 3.50 & 5.0 & 0.0 & 3.3183 & $-0.68 \%$ & 0.0000 & $0.00 \%$ & 0.1726 & $13.88 \%$ & 3.4909 & $0.04 \%$ \\
\hline $3-5-A$ & 3.50 & 5.0 & 45.0 & 3.3451 & $-0.20 \%$ & 11.7132 & $-0.05 \%$ & 0.1753 & $29.12 \%$ & 3.5204 & $1.26 \%$ \\
\hline $3-5-B$ & 3.50 & 5.0 & 35.0 & 3.3359 & $-1.01 \%$ & 7.7067 & $-1.25 \%$ & 0.1750 & $27.48 \%$ & 3.5109 & $0.41 \%$ \\
\hline $3-5-C$ & 3.50 & 5.0 & 25.0 & 3.3400 & $-0.78 \%$ & 4.7714 & $-1.24 \%$ & 0.1704 & $30.53 \%$ & 3.5104 & $0.74 \%$ \\
\hline $3-5-D$ & 3.50 & 5.0 & 15.0 & 3.3139 & $-1.34 \%$ & 2.5278 & $-1.37 \%$ & 0.1559 & $36.94 \%$ & 3.4698 & $0.38 \%$ \\
\hline $3-5-E$ & 3.50 & 5.0 & 5.0 & 3.3535 & $-1.74 \%$ & 0.8635 & $-1.22 \%$ & 0.1378 & $49.96 \%$ & 3.4912 & $0.30 \%$ \\
\hline $4-2-F$ & 4.60 & 2.0 & 0.0 & 4.6018 & $-2.51 \%$ & 0.0000 & $0.00 \%$ & 0.0150 & $786.50 \%$ & 4.6169 & $0.06 \%$ \\
\hline $4-2-A$ & 4.60 & 2.0 & 45.0 & 4.6663 & $-1.18 \%$ & 16.7201 & $1.25 \%$ & 0.0119 & $1072.31 \%$ & 4.6782 & $1.56 \%$ \\
\hline $4-2-B$ & 4.60 & 2.0 & 35.0 & 4.6688 & $-6.47 \%$ & 11.1260 & $-3.78 \%$ & 0.0121 & $1006.18 \%$ & 4.6809 & $-3.86 \%$ \\
\hline $4-2-C$ & 4.60 & 2.0 & 25.0 & 4.6253 & $-3.54 \%$ & 6.1195 & $-2.25 \%$ & 0.0131 & $932.70 \%$ & 4.6385 & $-0.89 \%$ \\
\hline $4-2-D$ & 4.60 & 2.0 & 15.0 & 4.6121 & $-2.43 \%$ & 3.2408 & $0.42 \%$ & 0.0127 & $953.33 \%$ & 4.6247 & $0.19 \%$ \\
\hline $4-2-E$ & 4.60 & 2.0 & 5.0 & 4.5816 & $-3.09 \%$ & 0.9654 & $3.58 \%$ & 0.0123 & $985.10 \%$ & 4.5939 & $-0.45 \%$ \\
\hline $4-10-F$ & 4.60 & 10.0 & 0.0 & 4.1223 & $-3.08 \%$ & 0.8121 & $0.00 \%$ & 0.4315 & $39.03 \%$ & 4.5538 & $0.91 \%$ \\
\hline $4-10-A$ & 4.60 & 10.0 & 45.0 & 4.1800 & $-5.92 \%$ & 15.6991 & $-3.14 \%$ & 0.4413 & $41.94 \%$ & 4.6212 & $-1.35 \%$ \\
\hline $4-10-B$ & 4.60 & 10.0 & 35.0 & 4.1940 & $-5.22 \%$ & 10.3238 & $-1.11 \%$ & 0.4348 & $44.07 \%$ & 4.6288 & $-0.59 \%$ \\
\hline $4-10-C$ & 4.60 & 10.0 & 25.0 & 4.2551 & $-4.93 \%$ & 6.0126 & $-1.52 \%$ & 0.4448 & $43.78 \%$ & 4.6998 & $-0.32 \%$ \\
\hline
\end{tabular}


Table 2: Trial results of Net Oil \& Gas Skid at TUV-NEL (continued).

\begin{tabular}{|c|c|c|c|c|c|c|c|c|c|c|c|}
\hline \multirow[b]{2}{*}{ Tag } & \multicolumn{3}{|c|}{ Nominal Experimental Conditions } & \multicolumn{2}{|c|}{ Oil Mass Flow } & \multicolumn{2}{|c|}{ Gas Mass Flow } & \multicolumn{2}{|c|}{ Water Mass Flow } & \multicolumn{2}{|c|}{ Liquid Mass Flow } \\
\hline & $\begin{array}{l}\text { Liq Mflow } \\
(\mathrm{kg} / \mathrm{s})\end{array}$ & $\begin{array}{c}\text { Water Cut } \\
\text { (\%) }\end{array}$ & $\begin{array}{l}\text { GVF } \\
\text { (\%) }\end{array}$ & $\begin{array}{c}\text { NEL } \\
\text { Reference } \\
(\mathrm{kg} / \mathrm{s})\end{array}$ & $\begin{array}{c}\text { Skid } \\
\text { Error } \\
(\%)\end{array}$ & $\begin{array}{c}\text { NEL } \\
\text { Reference } \\
(\mathrm{g} / \mathrm{s})\end{array}$ & $\begin{array}{c}\text { Skid } \\
\text { Error } \\
(\%)\end{array}$ & $\begin{array}{c}\text { NEL } \\
\text { Reference } \\
(\mathrm{kg} / \mathrm{s})\end{array}$ & $\begin{array}{c}\text { Skid } \\
\text { Error } \\
(\%)\end{array}$ & $\begin{array}{c}\text { NEL } \\
\text { Reference } \\
(\mathrm{kg} / \mathrm{s})\end{array}$ & $\begin{array}{c}\text { Skid } \\
\text { Error } \\
(\%)\end{array}$ \\
\hline $4-10-D$ & 4.60 & 10.0 & 15.0 & 4.1573 & $-4.39 \%$ & 3.1866 & $0.27 \%$ & 0.4292 & $43.70 \%$ & 4.5865 & $0.11 \%$ \\
\hline $4-10-E$ & 4.60 & 10.0 & 5.0 & 4.2537 & $-4.44 \%$ & 0.9503 & $1.32 \%$ & 0.4447 & $40.89 \%$ & 4.6984 & $-0.15 \%$ \\
\hline $4-95-F$ & 4.60 & 95.0 & 0.0 & 0.1894 & $-8.39 \%$ & 0.0000 & $0.00 \%$ & 4.3934 & $0.46 \%$ & 4.5828 & $0.09 \%$ \\
\hline $4-95-A$ & 4.60 & 95.0 & 45.0 & 0.1725 & $-1.12 \%$ & 12.5570 & $-2.21 \%$ & 4.4007 & $1.73 \%$ & 4.5732 & $1.62 \%$ \\
\hline $4-95-B$ & 4.60 & 95.0 & 35.0 & 0.1758 & $10.60 \%$ & 8.2667 & $-1.55 \%$ & 4.4524 & $0.85 \%$ & 4.6281 & $1.22 \%$ \\
\hline $4-95-C$ & 4.60 & 95.0 & 25.0 & 0.1772 & $14.70 \%$ & 5.1101 & $0.40 \%$ & 4.5323 & $0.85 \%$ & 4.7095 & $1.37 \%$ \\
\hline $4-95-D$ & 4.60 & 95.0 & 15.0 & 0.1733 & $19.24 \%$ & 2.8166 & $-0.15 \%$ & 4.4248 & $0.69 \%$ & 4.5981 & $1.39 \%$ \\
\hline $4-95-E$ & 4.60 & 95.0 & 5.0 & 0.2011 & $2.76 \%$ & 0.8855 & $1.23 \%$ & 4.3087 & $1.40 \%$ & 4.5098 & $1.46 \%$ \\
\hline $4-98-F$ & 4.60 & 98.0 & 0.0 & 0.0622 & $33.42 \%$ & 0.0001 & $0.00 \%$ & 4.5692 & $-0.38 \%$ & 4.6314 & $0.07 \%$ \\
\hline $4-98-A$ & 4.60 & 98.0 & 45.0 & 0.0599 & $27.37 \%$ & 13.0798 & $0.38 \%$ & 4.6202 & $2.02 \%$ & 4.6801 & $2.34 \%$ \\
\hline $4-98-B$ & 4.60 & 98.0 & 35.0 & 0.0701 & $55.94 \%$ & 8.6061 & $-1.90 \%$ & 4.5571 & $0.41 \%$ & 4.6272 & $1.25 \%$ \\
\hline $4-98-C$ & 4.60 & 98.0 & 25.0 & 0.0711 & $40.55 \%$ & 5.3281 & $-1.49 \%$ & 4.7304 & $0.10 \%$ & 4.8015 & $0.70 \%$ \\
\hline 4-98-D & 4.60 & 98.0 & 15.0 & 0.0746 & $42.83 \%$ & 2.8215 & $-1.79 \%$ & 4.5698 & $0.51 \%$ & 4.6444 & $1.19 \%$ \\
\hline $4-98-E$ & 4.60 & 98.0 & 5.0 & 0.0744 & $20.85 \%$ & 0.8645 & $-1.72 \%$ & 4.4977 & $0.53 \%$ & 4.5721 & $0.86 \%$ \\
\hline $5-20-F$ & 5.70 & 20.0 & 0.0 & 4.5200 & $-2.45 \%$ & 0.0003 & $0.00 \%$ & 1.2107 & $9.00 \%$ & 5.7307 & $-0.03 \%$ \\
\hline $5-20-A$ & 5.70 & 20.0 & 45.0 & 4.5065 & $-2.56 \%$ & 19.2667 & $1.00 \%$ & 1.2116 & $6.12 \%$ & 5.7181 & $-0.72 \%$ \\
\hline $5-20-B$ & 5.70 & 20.0 & 35.0 & 4.3877 & $-1.74 \%$ & 12.7030 & $0.24 \%$ & 1.2249 & $6.60 \%$ & 5.6126 & $0.08 \%$ \\
\hline $5-20-C$ & 5.70 & 20.0 & 25.0 & 4.4620 & $-3.00 \%$ & 7.8778 & $-2.64 \%$ & 1.2631 & $5.75 \%$ & 5.7250 & $-1.07 \%$ \\
\hline $5-20-D$ & 5.70 & 20.0 & 15.0 & 4.4885 & $-2.51 \%$ & 4.1703 & $-3.46 \%$ & 1.2779 & $6.65 \%$ & 5.7664 & $-0.48 \%$ \\
\hline $5-20-E$ & 5.70 & 20.0 & 5.0 & 4.4385 & $-2.10 \%$ & 1.2391 & $-3.72 \%$ & 1.2534 & $6.89 \%$ & 5.6919 & $-0.12 \%$ \\
\hline $5-90-\mathrm{F}$ & 5.70 & 90.0 & 0.0 & 0.4471 & $8.79 \%$ & 0.0000 & $0.00 \%$ & 5.2457 & $-0.80 \%$ & 5.6927 & $-0.05 \%$ \\
\hline 5-90-A & 5.70 & 90.0 & 45.0 & 0.4986 & $1.56 \%$ & 16.0306 & $2.45 \%$ & 5.1555 & $2.42 \%$ & 5.6541 & $2.34 \%$ \\
\hline $5-90-B$ & 5.70 & 90.0 & 35.0 & 0.4780 & $3.83 \%$ & 10.6482 & $-3.74 \%$ & 5.2508 & $-0.08 \%$ & 5.7288 & $0.25 \%$ \\
\hline 5-90-C & 5.70 & 90.0 & 25.0 & 0.4335 & $4.49 \%$ & 6.9862 & $-4.83 \%$ & 5.2430 & $1.08 \%$ & 5.6766 & $1.34 \%$ \\
\hline 5-90-D & 5.70 & 90.0 & 15.0 & 0.4597 & $8.89 \%$ & 3.7031 & $-6.01 \%$ & 5.3120 & $-0.47 \%$ & 5.7716 & $0.28 \%$ \\
\hline $5-90-E$ & 5.70 & 90.0 & 5.0 & 0.4662 & $3.07 \%$ & 1.1050 & $-2.54 \%$ & 5.2144 & $0.53 \%$ & 5.6806 & $0.74 \%$ \\
\hline $6-30-\mathrm{F}$ & 6.90 & 30.0 & 0.0 & 4.5891 & $-2.49 \%$ & 0.0000 & $0.00 \%$ & 2.3098 & $4.74 \%$ & 6.8989 & $-0.07 \%$ \\
\hline $6-30-B$ & 6.90 & 30.0 & 35.0 & 4.5466 & $-1.81 \%$ & 17.6429 & $4.93 \%$ & 2.3088 & $4.60 \%$ & 6.8554 & $0.35 \%$ \\
\hline
\end{tabular}


Table 2: Trial results of Net Oil \& Gas Skid at TUV-NEL (continued).

\begin{tabular}{|c|c|c|c|c|c|c|c|c|c|c|c|}
\hline \multirow[b]{2}{*}{ Tag } & \multicolumn{3}{|c|}{ Nominal Experimental Conditions } & \multicolumn{2}{|c|}{ Oil Mass Flow } & \multicolumn{2}{|c|}{ Gas Mass Flow } & \multicolumn{2}{|c|}{ Water Mass Flow } & \multicolumn{2}{|c|}{ Liquid Mass Flow } \\
\hline & $\begin{array}{l}\text { Liq Mflow } \\
\text { (kg/s) }\end{array}$ & $\begin{array}{c}\text { Water Cut } \\
\text { (\%) }\end{array}$ & $\begin{array}{l}\text { GVF } \\
(\%)\end{array}$ & $\begin{array}{c}\text { NEL } \\
\text { Reference } \\
(\mathrm{kg} / \mathrm{s}) \\
\end{array}$ & $\begin{array}{c}\text { Skid } \\
\text { Error } \\
(\%) \\
\end{array}$ & $\begin{array}{c}\text { NEL } \\
\text { Reference } \\
(\mathrm{g} / \mathrm{s}) \\
\end{array}$ & $\begin{array}{c}\text { Skid } \\
\text { Error } \\
(\%) \\
\end{array}$ & $\begin{array}{c}\text { NEL } \\
\text { Reference } \\
(\mathrm{kg} / \mathrm{s}) \\
\end{array}$ & $\begin{array}{l}\text { Skid } \\
\text { Error } \\
(\%) \\
\end{array}$ & $\begin{array}{c}\text { NEL } \\
\text { Reference } \\
(\mathrm{kg} / \mathrm{s}) \\
\end{array}$ & $\begin{array}{c}\text { Skid } \\
\text { Error } \\
(\%) \\
\end{array}$ \\
\hline $6-30-C$ & 6.90 & 30.0 & 25.0 & 4.6597 & $-2.99 \%$ & 9.4757 & $-2.41 \%$ & 2.2456 & $4.85 \%$ & 6.9053 & $-0.44 \%$ \\
\hline 6-30-D & 6.90 & 30.0 & 15.0 & 4.6671 & $-3.27 \%$ & 4.3756 & $-3.53 \%$ & 2.2871 & $5.03 \%$ & 6.9542 & $-0.54 \%$ \\
\hline $6-30-E$ & 6.90 & 30.0 & 5.0 & 4.6452 & $-2.67 \%$ & 1.1968 & $-1.96 \%$ & 2.2508 & $5.88 \%$ & 6.8960 & $0.12 \%$ \\
\hline $6-70-\mathrm{F}$ & 6.90 & 70.0 & 0.0 & 1.8367 & $-0.37 \%$ & 0.0000 & $0.00 \%$ & 5.0483 & $-0.23 \%$ & 6.8851 & $-0.27 \%$ \\
\hline 6-70-B & 6.90 & 70.0 & 35.0 & 1.7557 & $-1.52 \%$ & 12.9744 & $-3.43 \%$ & 5.1389 & $-2.43 \%$ & 6.8946 & $-2.20 \%$ \\
\hline $6-70-C$ & 6.90 & 70.0 & 25.0 & 1.7974 & $-0.42 \%$ & 7.2511 & $-9.63 \%$ & 5.0529 & $-1.91 \%$ & 6.8504 & $-1.52 \%$ \\
\hline 6-70-D & 6.90 & 70.0 & 15.0 & 1.7964 & $2.57 \%$ & 3.8374 & $-4.66 \%$ & 5.0697 & $-1.09 \%$ & 6.8661 & $-0.13 \%$ \\
\hline 6-70-E & 6.90 & 70.0 & 5.0 & 1.7703 & $2.96 \%$ & 1.3790 & $-8.66 \%$ & 5.1673 & $-2.49 \%$ & 6.9376 & $-1.10 \%$ \\
\hline $8-60-F$ & 8.00 & 60.0 & 0.0 & 2.8492 & $-1.62 \%$ & 0.0000 & $0.00 \%$ & 5.1322 & $1.05 \%$ & 7.9814 & $0.10 \%$ \\
\hline $8-60-C$ & 8.00 & 60.0 & 25.0 & 2.7882 & $2.20 \%$ & 8.8870 & $4.89 \%$ & 5.2021 & $1.34 \%$ & 7.9903 & $1.64 \%$ \\
\hline 8-60-D & 8.00 & 60.0 & 15.0 & 2.8499 & $-1.54 \%$ & 4.7072 & $-5.85 \%$ & 5.1991 & $-1.94 \%$ & 8.0490 & $-1.80 \%$ \\
\hline 8-60-E & 8.00 & 60.0 & 5.0 & 2.8257 & $-2.75 \%$ & 1.2181 & $-0.74 \%$ & 5.1836 & $-1.16 \%$ & 8.0093 & $-1.72 \%$ \\
\hline 9-10-F & 9.25 & 10.0 & 0.0 & 8.2802 & $-2.03 \%$ & 0.0000 & $0.00 \%$ & 0.9092 & $18.79 \%$ & 9.1894 & $0.03 \%$ \\
\hline 9-10-D & 9.25 & 10.0 & 15.0 & 8.3106 & $-3.36 \%$ & 7.6071 & $-3.57 \%$ & 0.8121 & $38.09 \%$ & 9.1227 & $0.33 \%$ \\
\hline $9-10-E$ & 9.25 & 10.0 & 5.0 & 7.8002 & $-3.96 \%$ & 2.0278 & $-2.87 \%$ & 0.6680 & $49.67 \%$ & 8.4681 & $0.27 \%$ \\
\hline $11-50-\mathrm{F}$ & 11.00 & 50.0 & 0.0 & 5.0280 & $-3.50 \%$ & 0.0000 & $0.00 \%$ & 5.8252 & $3.02 \%$ & 10.8532 & $0.00 \%$ \\
\hline 11-50-E & 11.00 & 50.0 & 5.0 & 5.0904 & $-2.85 \%$ & 2.5162 & $0.52 \%$ & 5.7912 & $2.49 \%$ & 10.8815 & $-0.01 \%$ \\
\hline
\end{tabular}




\section{References}

[1] Zamora, ME, H, and Henry, MP. "Digital Control of a Coriolis Mass Flow Meter”, IEEE Transactions on Industrial Electronics, Vol. 55, pp 2820-31, 2008.

[2] Röck, H., Koschmieder, F. “Model-Based Phasor Control of a Coriolis Mass Flow Meter (CMFM) for the Detection of Drift in Sensitivity and Zero Point”, in Recent Advances in Sensing Technology, Lecture Notes in Electrical Engineering Volume 49, 2009, pp 221-240.

[3] Röck, H., Koschmieder, F. “Operating a Coriolis Mass Flow Meter at two different Frequencies simultaneously using Phasor Control”, 10th International Symposium of Measurement Technology and Intelligent Instruments, Daejeon, Korea, June 2001.

[4] Henry, M.P., Clark, C., Duta, M., Cheesewright, R., Tombs, M.: "Response of a Coriolis mass flow meter to step changes in flow rate”, Flow Measurement and Instrumentation, Vol. 14 , pp 109-118, 2003.

[5] Clark C., Zamora, M.E., Cheesewright R., Henry, M.P. “The dynamic performance of a new ultra-fast response Coriolis flow meter”, Flow Measurement and Instrumentation 17, pp391-398, 2006.

[6] Tombs M, Henry, M, Zhou, F, Lansangan, R, Reese, M. "High precision Coriolis mass flow measurement applied to small volume proving”, Flow Measurement and Instrumentation 17, pp371-382, 2006.

[7] Henry, MP, Tombs, M, Duta, MD, Zhou, F, Mercado, R, Kenyery, F, Chen, J, Morles, M, Garcia, C. "Twophase flow metering of viscous oil using a Coriolis mass flow meter: a case study”, Flow Measurement and Instrumentation 17, pp399-413, 2006.

[8] Hemp, J, Sultan, G. "On the theory and performance of Coriolis mass flowmeters”, Proceedings of the International Conference on Mass Flow Measurement Direct and Indirect, 1989 Feb IBC Technical Services, London, 1989.

[9] Weinstein J, Kassoy D, Bell M. "Experimental study of oscillatory motion of particles and bubbles with applications to Coriolis flow meters”, Physics of Fluids 20, 2008.

[10] Hemp, J. and Kutin, J. "Theory of errors in Coriolis flowmeter readings due to compressibility of the fluid being metered”, Flow Measurement and Instrumentation 17, pp359-369, 2006.

[11] Gysling, D. L. “An aeroelastic model of Coriolis mass and density meters operating on aerated mixtures, Flow Measurement and Instrumentation 18, pp69-77, 2007.

[12] Thomsen, J.J. and Dahl, J. “Analytical predictions for vibration phase shifts along fluid-conveying pipes due to Coriolis forces and imperfections”, Journal of Sound and Vibration 329, pp3065-3081, 2010.

[13] Enz, S., Thomsen, J. J., Neumeyer, S. "Experimental investigation of zero phase shift effects for Coriolis flowmeters due to pipe imperfections”, Flow Measurement and Instrumentation, 22, pp1-9, 2011.

[14], Agar, J. “New Coriolis-based Multiphase Flow Meter for Heavy-Oil Mature Fields”, SPE Russian Oil and Gas Conference and Exhibition, 26-28 October 2010, Moscow, Russia.

[15] Liu, R P, Fuent, M J, Henry, MP \& Duta, MD. “A neural network to correct mass flow errors caused by two-phase flow in a digital Coriolis mass flowmeter”, Flow Measurement \& Instrumentation, 12, pp53-63, 2001. 
[16] Tombs, MS, Henry, MP, Duta, MD, Lansangan, R, Dutton, RE, Mattar, WM, “Multiphase Coriolis Flowmeter”, US Patent 7,188,534. 2007.

[17] Vortab Product Brochure. http://www.vortab.com/pdfs/Vortab-Brochure-RevE.pdf . Accessed 14/12/12.

[18] Weatherford. Red Eye MP Water Cut Meter. Product Brochure.

http://www.weatherford.com/weatherford/groups/web/documents/weatherfordcorp/wft096554.pdf, Accessed $14 / 12 / 12$.

[19] EN ISO 12213-2:2005: Natural gas - calculation of compression factor. 2005.

[20] GSSSD MP 113-03. "Determination of the density, compressibility factor, the adiabatic index and the coefficient of dynamic viscosity of the wet gas in the temperature range $263 \ldots 500 \mathrm{~K}$ at pressures to $15 \mathrm{MPa}$." All-Russian Research Center for Standardization, Information and certification of raw materials and substances of Gosstandart of Russia (Federal State Unitary Enterprise VNITSSMV), 2003.(in Russian)

[21] API MPMS Chapter 11.1-2004. "Manual of Petroleum Measurement Standards Chapter 11—Physical Properties Data Section 1-Temperature and Pressure Volume Correction Factors for Generalized Crude Oils, Refined Products, and Lubricating Oils.”. May 2004, Addendum 1 Sept 2007. American Petroleum Institute, API Publishing Services, 1220 L Street, N.W., Washington, D.C. 20005.

[22] GOST R 8.615, Amended 2008. State system for ensuring uniformity of measurements. Measurement of quantity of oil and petroleum gas extracted from subsoil. General metrological and technical requirements. Federal Agency for technical regulation and metrology. 2008. (in Russian) 